\title{
Neuroplasticity and the next wave of antidepressant strategies
}

\section{Shawn Hayley* and Darcy Litteljohn}

Department of Neuroscience, Carleton University, Ottawa, ON, Canada

\section{Edited by:}

Lawrence Rajendran, University of Zurich, Switzerland

Reviewed by:

Maria Passafaro, University of Milano, Italy

Jon Storm-Mathisen, University of Oslo, Norway

\section{*Correspondence:}

Shawn Hayley, Department of

Neuroscience, Carleton University,

1125 Colonel By Drive, Ottawa, K1S

$5 B 6$ ON, Canada

e-mail: shayley@ccs.carleton.ca
Depression is a common chronic psychiatric disorder that is also often co-morbid with numerous neurological and immune diseases. Accumulating evidence indicates that disturbances of neuroplasticity occur with depression, including reductions of hippocampal neurogenesis and cortical synaptogenesis. Improper trophic support stemming from stressor-induced reductions of growth factors, most notably brain derived neurotrophic factor (BDNF), likely drives such aberrant neuroplasticity. We posit that psychological and immune stressors can interact upon a vulnerable genetic background to promote depression by disturbing BDNF and neuroplastic processes. Furthermore, the chronic and commonly relapsing nature of depression is suggested to stem from "faulty wiring" of emotional circuits driven by neuroplastic aberrations. The present review considers depression in such terms and attempts to integrate the available evidence indicating that the efficacy of current and "next wave" antidepressant treatments, whether used alone or in combination, is at least partially tied to their ability to modulate neuroplasticity. We particularly focus on the N-methyl-D-aspartate (NMDA) antagonist, ketamine, which already has well documented rapid antidepressant effects, and the trophic cytokine, erythropoietin (EPO), which we propose as a potential adjunctive antidepressant agent.

Keywords: depression, relapse, ketamine, erythropoietin, combined treatment, neurogenesis, BDNF
This special issue entitled "Neuroimmune modulation for brain plasticity and repair" essentially deals with how immune and trophic factors differentially influence pathological brain situations, with a view towards informing the development of novel disease-modifying therapies. In particular, whereas certain key growth factors such as brain-derived neurotrophic factor (BDNF) have pro-neuroplastic and neuroprotective actions, pro-inflammatory stimuli (particularly certain cytokines) exert predominantly anti-neuroplastic and pro-death effects. This relationship appears to hold across a range of central conditions, including major depression, anxiety disorders, Parkinson's disease (PD), Alzheimer's disease (AD), multiple sclerosis (MS), and traumatic brain injuries. Immune-based strategies aimed at limiting the actions of pro-inflammatory factors and/or stimulating those of key growth factors may therefore hold particular promise for treating chronic brain disease.

In this review article we focus specifically on recent advances in the treatment of depressive illness, exploring in detail how trophic mediators, modulators and mechanisms may be relevant for antidepressant action. Depression is particularly germane to this special issue given not only its strong link with trophic/inflammatory factors, but also the fact that the disorder is highly co-morbid with most neurological diseases. Indeed, onethird to one-half of all PD patients has major depression (Rojo et al., 2003; Yamanishi et al., 2013), and a similar proportion of
$\mathrm{AD}$ and MS patients likewise suffers from the condition (Holtzer et al., 2005; Siegert and Abernethy, 2005). It is very likely that such high rates of co-morbid depressive symptomology are at least partially attributable to the common pro-inflammatory state evident in these brain conditions. In fact, during MS relapses (in the most common relapsing-remitting form of the disease) when pro-inflammatory levels are highest, depressive symptoms also tend to peak (Kahl et al., 2002; Koutsouraki et al., 2011). Moreover, in PD patients, retrospective studies indicated that signs of depression were often evident years before the onset of motor symptoms or PD diagnosis (Jacob et al., 2010). Hence, depression in at least a subset of PD cases probably stems from antecedent pathological changes (during the so-called prodromal period) occurring most likely outside of the basal ganglia motor circuitry (Litteljohn et al., 2010). There is in this regard a growing recognition that, in the PD brain, Lewy body pathology occurs early—and probably even starts—in brainstem and limbic nuclei (Goedert et al., 2013). As is the case for senile plaques in $\mathrm{AD}$, these $\alpha$-synuclein-containing inclusion bodies, which are hallmark signs of PD, are almost universally associated with robust microglial activation and elevated levels of inflammatory cytokines (Reynolds et al., 2008; Phani et al., 2012). Thus, earlyoccurring pro-inflammatory changes might be one common mechanism accounting for co-morbid depressive and potentially other neuropsychiatric symptoms across a range of neurological disease states. 
It could be argued that an enhanced neuroinflammatory tone stemming from primary disease pathology or possibly even psychosocial stressor exposure might set the stage for depression by causing alterations in the function or abundance of key trophic factors implicated in normal neuroplastic and pro-survival events (or by simply overtaxing them). Indeed, depressive behaviors provoked by interferon- $\alpha$ (IFN- $\alpha$ ) and interleukin-1 $\beta$ (IL-1 $\beta$ ) were associated with reduced BDNF levels and reductions of hippocampal neurogenesis, and these effects normalized upon administration of the IL- $1 \beta$ receptor antagonist, IL-1ra (Anisman et al., 2008; Dedoni et al., 2012). Similarly, treatment with the bacterial endotoxin, lipopolysaccharide (LPS), or the viral mimic, polyinosinic-polycytidylic acid (polyI:C), augmented central (hippocampus, frontal cortex) and peripheral pro-inflammatory cytokine concentrations whilst reducing BDNF levels, and these effects coincided with pronounced memory deficits (Kranjac et al., 2012) and depressivelike behaviors (Gibney et al., 2013). In fact, infection with live influenza virus induced changes analogous to those provoked by the LPS and polyI:C challenges (Jurgens et al., 2012), and a recent study by Ji et al. (2011) likewise implicated disturbed pro-inflammatory cytokine-neurotrophin crosstalk in the cognitive impairment following chronic amyloid- $\beta$ treatment in mice.

Secondary to or at least facilitated by such inflammatorydriven perturbations of trophic signaling, inadequate or improper neural connections could conceivably be recruited and engaged to deal with the "wear and tear" of life's stressors. If one takes the point of view that depression stems, at least in part, from faulty wiring of emotional and fear sensitive circuitry within the brain, then it stands to reason that finding the means to "re-wire" such circuitry and maintain these changes is the key to addressing the fundamental biological basis for the condition. Hence, using cognitive behavioral and other psychotherapeutic methods in addition to pharmacological treatments that directly target biological processes linked to faulty neural wiring may be essential for adequate treatment.

Consistent with the theme of this special issue, it is our contention that immune- and- stressor-induced changes in neuroplasticity, involving adult neurogenesis, synaptogenesis, dendritic remodeling, and trophic signaling, are ultimately responsible for the biological manifestations of the "faulty wiring" posited to occur in depression. The present review will target two key aspects of this hypothesis. Firstly, we will review the data in favor of a neuroplastic-trophic hypothesis for depression and integrate them with new evidence indicating that traditional monoamine acting drugs act through neuroplastic processes to provoke therapeutic effects. Secondly, we explore in detail novel emerging treatments for depression that may more directly target neuroplastic circuits and act to at least temporarily "re-wire" neural circuits at the systems levels. As an example, emerging evidence suggests that certain agents with novel antidepressant properties, such as ketamine, might modify the connectivity of diverse cortical circuitry involved in the generation of consciousness, sense of self and potentially rumination. We will also introduce the possibility that certain immune cytokines that have trophic properties [e.g., erythropoietin (EPO)] might contribute novel antidepressant properties consistent with a neuroplastic view of depression.

\section{NEUROPLASTICITY AND DEPRESSION: A ROLE FOR EXISTING ANTIDEPRESSANTS NEUROPLASTICITY AND RUMINATION}

Neuroplastic changes at the molecular and cellular level must eventually come to reverberate through neural circuits at the systems level. Indeed, meaningful changes in behavior, thought patterns and emotions are complex and require concerted communication between multiple brain regions. In this regard, the recent breakthrough in our understanding of the basic neuronal circuitry that gives rise to our "default" or "resting state" has caused a substantial paradigm shift in how we view consciousness, self-referential thinking (introspection) and ruminative processes. The so-called default mode network (DMN) comprises a series of interconnected cortical brain regions that are highly active during restful or un-challenged states (e.g., insula, cingulate, frontal and parietal regions). However, during goal- and- task-oriented activity, when specific thalamo-cortical pathways are engaged to appropriately deal with the task at hand, the DMN regions deactivate or reduce their metabolic activity (Raichle et al., 2001). Interestingly, this task-associated shifting between DMN rest state and alternative activation pathways appears to be disrupted in depressed patients (Sheline et al., 2009; Sliz and Hayley, 2012). Specifically, such individuals fail to appropriately down-regulate DMN activity and, hence, get "stuck" in self-focused states and have difficulty smoothly shifting to the required task. This is likely the neural machinery that contributes to the increased negative ruminations evident in depression.

It is possible that disturbances of neuroplasticity within DMN brain regions could contribute to faulty reverberations of this circuit, which with repeated activation would only serve to strengthen negative ruminations in depressed individuals. However, a very recent study offers hope that antidepressant drug treatments might target the DMN to help "re-wire" faulty circuitry. Specifically, Scheidegger et al. (2012) reported that ketamine treatment reduced DMN metabolic activity and diminished DMN connectivity within the cingulate and prefrontal cortices, albeit in healthy non-depressed participants. One could easily imagine that such an effect of ketamine and potentially other antidepressant drugs could help give depressed patients the needed "push" to move them out of a current negative ruminative state, and enable them to derive benefit from completing external tasks or otherwise focusing on or engaging with positive environmental stimuli. Ultimately, such positive interactions would be expected to help foster or strengthen appropriate emotional neural connections and promote synaptogenesis (as has been reported with ketamine treatment) in brain regions adversely affected by the stress and negative thinking associated with depression.

The importance of rumination in the depressive response must not be underestimated, and the sad fact is that excessive rumination over one's negative plight and ways to "fix" the situation actually likely strengthens the very depressiogenic pathways that give rise in the first place to the low mood and host of other depressive 
symptoms. Hence, a better understanding of how neuroplastic changes at a cellular level translate into reverberations of systems that influence and/or underpin rumination is key to finding more effective and rapid means of ameliorating depression, as well as its co-morbid anxiety symptoms. Although cognitive behavioral techniques for learning how to break out of ruminative cycles are undoubtedly of substantial importance, when in the throes of depression such strategies may seem entirely untenable and are therefore perhaps more useful during continuation and maintenance stages to prevent relapse once the illness is more under control. To this end, ketamine and the development of similar rapid neuroplastic modulator drugs could be just the solution to the ruminative crisis.

\section{NEUROPLASTICITY, DEPRESSION AND RELAPSE}

An important but often overlooked aspect of depression is the high degree of relapse that occurs even in individuals that initially responded well to antidepressant drugs. As such, some enduring neural changes might underlie the presumed pathological brain circuits. In this regard, considerable evidence has supported the contention that protracted disturbances of neuroplasticity might occur in depression. In particular, major depression is associated with both structural and functional changes within discrete brain regions, including the hippocampus, amygdala and prefrontal cortex (PFC; Drevets et al., 2008; Sacher et al., 2012). Particular attention has focused on the reduced hippocampal volume often observed in patients diagnosed with major depression, and postmortem as well as brain imaging analyses indicated that the extent of the hippocampal reduction was related to illness duration (Bremner et al., 2000; MacQueen et al., 2003; Colla et al., 2007). Recent evidence has highlighted the possibility that persistent alterations of neuroplasticity result in faulty communication between anterior cingulate cortex (ACC), PFC, hippocampal, and amygdaloid regions-thus giving rise to disturbed processing of emotionally salient information (Schlösser et al., 2008; Carballedo et al., 2011).

A particularly important point to consider is the fact that the reductions in regional brain volume that are evident in depression can be effectively reversed with successful treatment to remission (Banasr et al., 2011; Arnone et al., 2012). Thus, structural anomalies in depression need not necessarily be permanent, underscoring the importance of early intervention to stave off enduring and potentially even progressive brain damage. The possibility has been entertained that reductions of neurogenesis and their correction with antidepressant treatment might be one mechanism accounting for hippocampal volume variations (Malberg, 2004; Boldrini et al., 2009). Of course, the relatively low number of new neurogenic cells normally produced in adulthood suggests that this is not the only process involved [the exciting recent discovery by Spalding et al. (2013) that a full third of hippocampal neurons are subject to exchange across the human lifespan strongly hints, however, at an important functional role of adult neurogenesis in health and disease]. Other findings have indicated that changes in glial cell density and the complexity of dendritic arbors might also account for volumetric changes in depression (Tata and Anderson, 2010; Gittins and Harrison, 2011). Indeed, reductions of cortical and/or hippocampal astrocytes were reported in depressed patients (Rajkowska et al., 1999; Rajkowska, 2000, as well as in stressor-based animal models of the disease (Banasr et al., 2010; Liu et al., 2011). Stressors also have well known inhibitory actions on dendritic branching (e.g., Son et al., 2012), raising the possibility that grey matter shrinkage may be related at least in part to the considerable stress experienced by depressed patients. In fact, Hercher et al. (2010) reported that depressed patients who committed suicide displayed reduced dendritic length of pyramidal neurons in the ACC.

These different scenarios are not mutually exclusive; whatever the case, it is still unclear as to whether regional brain volume reductions are causally implicated in depression or arise from some secondary aspect of the illness. At the very least, grey and/or white matter volumetric changes provide a useful biomarker for the structural state of the brain and potentially the duration of depressive illness (Cheng et al., 2010; Arnone et al., 2012). Further, the degree of volume reduction could possibly provide information regarding the likelihood of positive treatment responses and, conversely, the risk of relapse. Future studies are needed to assess if and how such structural changes map onto the probability of relapse, especially since it is easy to envision that volumetric reductions could give rise to faulty processing of emotional stimuli, as well as potentially contribute to ruminations.

In addition to reductions of neuroplasticity, it should be underscored that increased neuroplasticity could, in certain cases, contribute to depressive symptomology and relapse. This is analogous to the case of addictive behaviors, wherein "negative" plasticity represents a re-wiring of hedonic and craving pathways. This point is perhaps best illustrated in the case of the amygdala, which displays increased dendritic arborization in response to stressors rather than the reductions observed in the PFC and hippocampus (Vyas et al., 2002). Stressors were likewise reported to increase BDNF levels in the amygdala whilst reducing them in the hippocampus (Lakshminarasimhan and Chattarji, 2012). Similarly, while BDNF had antidepressant-like effects when administered directly into the hippocampus (Shirayama et al., 2002; Ye et al., 2011), it actually provoked depressive-like behaviors when infused into the ventral tegmental area (VTA) (the source of dopaminergic innervation of the PFC and limbic nuclei) (Eisch et al., 2003). Enhanced plasticity of amygdaloid nuclei could increase vulnerability to depression by virtue of augmented "fear" or threat processing. In fact, BDNF signaling is known to be required for amygdala-dependent fear learning in rodents (Rattiner et al., 2004; Ou and Gean, 2006). This would be especially important in the context of relapse given that depressed individuals in remission often display heightened vigilance and arousal; even modest stressors could engender small relapses that if not immediately dealt with could progress to full-fledged relapse. It may be that enhanced negative plasticity persists in the VTA or amygdala among some (or all) individuals with a history of depression, and underlies these individuals' heightened vulnerability to relapse.

\section{NEUROTROPHIC FACTORS, DEPRESSION AND ANTIDEPRESSANT RESPONSES}

Several reports have indicated that platelet and serum BDNF protein concentrations are suppressed in depressed subjects, with 
levels of the growth factor correlating with symptom severity (Pandey et al., 2010; Yoshida et al., 2012). BDNF mRNA expression was similarly decreased in leukocytes of depressed patients, and treatment with the selective serotonin reuptake inhibitor (SSRI), escitalopram, normalized this deficit (Cattaneo et al., 2010). Moreover, in clinical populations, patient improvement coincided with plasma and serum BDNF returning to normal levels (Piccinni et al., 2008; Teixeira et al., 2010). Interestingly, BDNF in circulating lymphocytes was even suggested as a possible biomarker to predict antidepressant treatment response (venlafaxine) (Rojas et al., 2011).

Animal models have extended the human findings to include impaired hippocampal neurogenesis and aberrant neuronal morphology in the discussion of neurotrophic and neuroplastic mechanisms in depression. Indeed, impaired hippocampal neurogenesis was evident in rodents exposed to a chronic corticosterone or stressor regimen (McEwen, 2005; Diniz et al., 2013), and hippocampal implantation of cortisol pellets among vervet monkeys induced irregular cell layers, soma shrinkage and dendritic atrophy (Sapolsky et al., 1990). Likewise, in subordinate male tree shrews, psychosocial stress caused a reduction in the complexity of apical dendrites (both dendrite length and number of branch points) on pyramidal hippocampal and PFC neurons (Magariños et al., 1996). Importantly, stressor exposure in animals (using a wide variety of stressor preparations) has been routinely found to alter central BDNF protein and/or mRNA levels, and these BDNF changes are considered to be instrumental for the negative effects of stressors on neurogenesis and neuronal morphology and cytoarchitecture (Masi and Brovedani, 2011).

Besides their potentiating effects on circulating BDNF, several clinically beneficial therapies, including SSRIs, tricyclics, and electroconvulsive therapy (ECT), were reported to augment hippocampal BDNF expression (Castrén et al., 2007). In fact, it would appear that the vast majority of known effective antidepressant treatments stimulate BDNF and affect neurogenesis. For instance, all SSRIs and tricyclic antidepressants, as well as new alternate treatments such as vagal stimulation and deep brain stimulation (DBS), positively influence hippocampal neurogenesis (Castrén and Rantamäki, 2010; Encinas et al., 2011; Yan et al., 2011). Similarly, aerobic exercise and enriched environments typically increase hippocampal BDNF, and their antidepressant-like effects in the context of a stressor depend upon intact neurogenesis (Ernst et al., 2006; Schloesser et al., 2010). Furthermore, direct brain infusion of BDNF (considered a neurotrophic cytokine itself) promoted sprouting of central serotonin (5-HT) neurons (Mamounas et al., 1995) and, when administered directly into the hippocampus, the neurotrophin produced antidepressant-like behavioral effects (Shirayama et al., 2002).

Despite the rather strong evidence linking antidepressant drug responses to BDNF, recent work has uncovered several notable exceptions. For instance, the tricyclic desipramine did not affect PFC or hippocampal BDNF, and escitalopram actually decreased BDNF levels in these brain regions (Jacobsen and Mørk, 2004). Further, while one week of escitalopram increased BDNF mRNA, three weeks led to a reduction of transcript levels in the hippocampus (Alboni et al., 2010). These findings clearly contrast with other studies demonstrating antidepressant drug-induced elevations of BDNF both in the basal state and in response to chronic stress (Balu et al., 2008; Zhang et al., 2010). Some of the discrepancies between findings in BDNF studies might be related to the fact that the protein is enzymatically processed in such a complex manner. Indeed, there are believed to be nine different promoters controlling BDNF transcription and it has been predicted that there may be 22 different BDNF mRNA isoforms (Zheng et al., 2012). There is also evidence to suggest that BDNF protein and mRNA follow distinct temporal patterns of induction upon antidepressant administration. For instance, Musazzi et al. (2009) showed that BDNF protein levels were increased in the hippocampus and PFC after 1-2 weeks of reboxetine treatment, whereas the BDNF mRNA elevation only became apparent after 3 weeks. A further complicating issue is the fact that typical antidepressant treatments appear unable to influence BDNF release in an activity-dependent manner. This could help explain the characteristic time lag in therapeutic action of many of these drugs, given that rapid antidepressant actions have been linked to a rapid BDNF response (Duman et al., 2012). Ultimately, differences in the timing of exposure and the nature of the antidepressant or other eliciting stimulus likely uniquely influence the post-translational processing of BDNF, as well as the transcriptional machinery recruited to the BDNF promoter and other regulatory regions.

Although BDNF has undoubtedly received the most attention, emerging and recent evidence indicates that other growth factors, most notably glial cell-line derived neurotrophic factor (GDNF) (a member of the transforming growth factor beta family) is also likely involved in depression. Indeed, GDNF protein and mRNA levels were diminished in the blood of depressed patients (especially in later life) (Takebayashi et al., 2006; Otsuki et al., 2008; Diniz et al., 2012; Tseng et al., 2013), and successful antidepressant treatment (e.g., with SSRIs, ECT) caused a return to normal levels (Zhang et al., 2008, 2009). Yet, Wang et al. (2011a) found that higher levels of plasma GDNF correlated with cognitive impairment in late-onset depression, and Michel et al. (2008) reported finding increased GDNF concentrations in the parietal cortex among autopsied depressed patients. Thus, similar to the case of BDNF, it appears that the relationship between GDNF and depression may be more nuanced and complex than perhaps initially thought, and compensatory processes are likely involved.

Nonetheless, in rodents, antidepressants were found to not only normalize stressor-induced reductions in circulating GDNF (Angelucci et al., 2003) but also to induce the neurotrophin's synthesis and release from cultured glioma cells and astrocytes (Mercier et al., 2004; Golan et al., 2011; Di Benedetto et al., 2012). Similarly, hippocampal GDNF levels were markedly diminished in rats exposed to chronic stress, and clomipramine treatment (a tricyclic agent) reversed this deficit whilst ameliorating the stressor-induced behavioral symptoms (Liu et al., 2012). Interestingly, Uchida et al. (2011) recently reported that chronic stress caused changes in histone modification and DNA methylation of the GDNF gene promoter within the mouse ventral striatum. What's more, these epigenetic modifications proved to be critical in determining susceptibility (or resistance) to the depressiveand- anxiety-like behavioral effects of the stressor (Uchida et al., 2011). In light of these findings and given the critical role ascribed 
to GDNF in the development and function of hippocampal cells, it is possible that alterations of GDNF are relevant for the "plasticity deficit" that appears in depression. Indeed, continuous infusion of GDNF into the striatum markedly increased cell proliferation and neurogenesis in the adult canine hippocampal dentate gyrus (Chen et al., 2005). And more recently, Kohl et al. (2012) showed that chronic fluoxetine treatment robustly stimulated adult hippocampal neurogenesis among $\alpha$-synculeinoverexpressing mice (which display profound basal impairments in neurogenesis) via the induction of hippocampal BDNF and GDNF.

\section{POLY-TREATMENT APPROACHES IN DEPRESSION}

It has become clear that poly-drug treatment strategies often lead to a greater likelihood of remission and reduce the risk of depressive relapse (Blier et al., 2010; El Mansari et al., 2010). This is not altogether surprising given the wide spectrum of physical and emotional symptoms typically experienced by patients. Indeed, the neurovegetative symptoms of depression, which include disturbed sleep and feeding, as well as agitation and psychomotor retardation, are clearly rooted in neural pathways that are distinct from those subserving the cognitive and emotional aspects of the disease (e.g., melancholia, anhedonia). A polypharmacy approach in depression thus allows for the tailoring of treatment to the individual (i.e., based on the specific symptom clusters exhibited by each patient). For instance, augmentation of SSRI and serotoninnorepinephrine reuptake inhibitor (SNRI) treatments with lowdose atypical antipsychotics (e.g., risperidone, aripiprazole) has been shown to not only boost the basic antidepressant response on mood (especially among treatment-resistant and/or suicidal patients) but also to greatly diminish anxiety and neurovegetative symptoms (Reeves et al., 2008; Trivedi et al., 2008; Blier and Blondeau, 2011; Chen et al., 2011; Owenby et al., 2011). At the same time, combining SSRIs with atypical antidepressants such as mirtazapine also greatly alleviates certain neurovegatative features, particularly disturbed sleep (Holm and Markham, 1999; Blier et al., 2009; Jindal, 2009). Ultimately, the heterogeneity in both symptom profile and response profile to the various SSRIs probably stems from the complexity of genetic backgrounds in depression, as well as wide variation in depressed patients' history of prior stress.

Besides having the advantage of affecting - at times synergistically-multiple different mood-relevant neurotransmitter systems (e.g., 5-HT, norepinephrine (NE) and dopamine (DA); El Mansari et al., 2010; Masana et al., 2012), evidence is beginning to suggest that multi-drug treatments may induce more robust, rapid and/or long-lasting neuroplastic changes than single-drug treatments. For instance, imipramine-plusmetyrapone (a glucocorticoid synthesis inhibitor), which showed therapeutic promise in animal models and a treatment-resistant human sample, caused a synergistic increase in BDNF mRNA expression within rat hippocampus and cortex (Rogóz and Legutko, 2005). More recently, augmentation of fluoxetine with the 5-HT2A receptor antagonist, ketanserin, induced a more potent increase of hippocampal BDNF mRNA and $\beta$ catenin protein (which is important for cellular proliferation and differentiation during development and repair) than either drug alone, and these effects coincided with diminished forced swim immobility (Pilar-Cuéllar et al., 2012). Similarly, Marchetti et al. (2010) demonstrated that subchronic combinatorial imipramine and rolipram (a phosphodiesterase type 4 inhibitor) synergistically reduced immobility in the forced swim test (FST) and potentiated activity-dependent transcription in the hippocampus. Moreover, the combination treatment augmented glutamatergic transmission in hippocampal CA1 pyramidal neurons and increased the dendritic spine density of these cells; long-term potentiation at CA1 synapses was also enhanced Marchetti et al. (2010). And finally, using a chronic stress rat model of depression, Xu et al. (2006) revealed that the atypical antipsychotic, quetiapine, and the SNRI, venlafaxine, acted synergistically and at relatively low doses to prevent the stressorinduced reductions in hippocampal neurogenesis and BDNF expression. Thus, it is likely that the heightened therapeutic response engendered by multi-drug preparations stems, at least in part, from the additive and synergistic effects of these treatments on a range of cellular and molecular neuroplastic processes.

Evidence is also beginning to suggest that atypical and secondgeneration antidepressants, aside from being useful as "addons" in augmentation therapy (or as later-line but sometimes even first-line monotherapies), could be helpful in alleviating some of the side effects induced by traditional antidepressant medicines [see Bauer et al. (2013) for a good recent review of the major side effects associated with typical and newer generation antidepressants]. For instance, Ozmenler et al. (2008) reported that mirtazapine augmentation in remitted depressed patients with SSRI treatment-emergent sexual dysfunction led to a significant reduction of depressive symptoms and, in nearly half the cases, completely ameliorated the SSRI-induced sexual problems. More generally, it was suggested that combination antidepressant therapy might allow for lower doses of the separate component drugs to be used (relative to monotherapy), which could improve patient tolerability and adherence to treatment (Goodwin et al., 2009). Yet, it should be underscored that many of the prospective and accepted adjunctive agents, particularly the atypical antipsychotics, are themselves associated with potentially severe adverse effects (Nelson and Papakostas, 2009; Bauer et al., 2013). Moreover, a polypharmacy approach to treating depression is necessarily associated with an increased risk of drug-drug interactions; this is especially so among individuals already taking multiple medications-older persons and HIV-infected patients receiving antiretroviral therapy, for instance (Hill and Lee, 2013).

Another strategy for treating depression that has garnered substantial clinical and research interest is the combining of pharmacological and psychotherapeutic modalities (usually interpersonal or cognitive behavioral therapy; CBT). Over the years there have been numerous studies supporting the clinical effectiveness of such an approach, especially in cases of chronic major depression (de Maat et al., 2007). Recently for instance, Köhler et al. (2013) reported that CBT augmentation markedly improved clinical outcomes among acutely depressed patients receiving pharmacological treatment in a naturalistic psychiatric setting. Moreover, a large-scale randomized controlled trial of the effectiveness of CBT augmentation to pharmacotherapy in treatment- 
resistant depression yielded strikingly positive results (Wiles et al., 2013). Data pointing to a beneficial effect of antidepressantsplus-psychotherapy in the initiation and/or continuation phases of treatment likewise exist for child and adolescent populations (Kennard et al., 2008; Lynch et al., 2011), as well as for depressed geriatric patients (Hollon et al., 2005). It is somewhat surprising then that several recent meta-analyses failed to provide compelling evidence (either sparse or none at all) in support of combined psychotherapy and pharmacotherapy in depression (Imel et al., 2008; Cox et al., 2012; Cuijpers et al., 2012; Jakobsen et al., 2012; von Wolff et al., 2012). However, it should be noted that most if not all of these meta-analyses were limited by the small number of published randomized controlled trials meeting inclusion criteria (limited data availability), as well as the relatively small sample sizes used in the included reports (limited power).

Importantly, just as pharmacological treatments have been shown to normalize regional brain functional abnormalities in depression (e.g., Mayberg et al., 2000; Heller et al., 2013), so too have several of the more common psychological therapies used for treating the disease (e.g., CBT). Even long-term psychodynamic interventions were linked to persistent neurobiological changes in depressed patients (Buchheim et al., 2012). In a recent systematic review on the subject, Quidé et al. (2012) set forth compelling evidence that both pharmacological and psychological treatments normalize functional (and in the former, structural too) alterations of a wide-ranging "fear network" in the depressed and anxious brain, and that these common ends are most likely achieved through divergent means. Specifically, whereas antidepressant drugs tend to decrease limbic hyperactivity (and, consequently, emotional reactivity), "talk therapy" appears to work by strengthening, building and restoring frontal cortex capacity (i.e., for self-referential processing and emotional regulation), particularly in the ACC and medial PFC (Ritchey et al., 2011; Quidé et al., 2012; Yoshimura et al., 2013). Clearly, distinct yet convergent neuroplastic mechanisms are likely involved in the antidepressant action of pharmacological (primarily "bottomup") and psychological (more "top-down") therapies, and there is a potential, therefore, for additive or even synergistic crossmodal antidepressant effects. This could be relevant not only for treatment initiation but also relapse prevention and maintenance of the antidepressant response over time.

Although a considerable degree of success has been had in recent years using combinatorial treatments of existing antidepressant treatments, there remains a desperate need for the development of novel pharmacological, genetic and other agents. This is especially fuelled by the significant number of treatmentresistant patients (only some of whom respond to combination therapy with extant treatments), as well as the recent surge in experimental and clinical studies demonstrating that, besides monoaminergic and hormonal alterations, reductions in trophic factors (particularly BDNF) together with fundamental disturbances in various elements of neuroplasticity might contribute to the development and evolution of depression. To this end, we now turn our attention to emerging evidence demonstrating the potential antidepressant efficacy of two novel agents, ketamine and EPO-both of which appear to greatly affect neuroplastic processes.

\section{NOVEL ANTIDEPRESSANT TREATMENTS TO TARGET NEUROPLASTICITY FROM A CELLULAR TO SYSTEMS LEVEL: A FOCUS ON KETAMINE AND ERYTHROPOIETIN}

The search for novel antidepressants with targets outside of the monoaminergic pathways has gained momentum in recent years. Indeed, evidence has begun to reveal that aside from the typical 5-HT, NE and DA circuits, multiple other systems appear to be affected in depression. There is, for instance, a growing recognition that stress neuropeptide systems, most notably the corticotropin-releasing hormone $(\mathrm{CRH})$ signaling network, are dysregulated in depression, and recent attempts have been made to develop antidepressant agents that antagonize the actions of $\mathrm{CRH}$ and its related peptides (Holsboer and Ising, 2010). Non-pharmacological depression treatments that influence neuroplasticity have also begun to emerge; these include DBS (as a late-line option in severe cases), transmagnetic stimulation (TMS) and vagal stimulation. Of course, ECT has long been considered a potent inducer of neuroplasticity (though fraught with potentially serious side effects), and psychotherapeutic modalities too are beginning to be conceptualized in terms of their neuroplastic potential (Beauregard, 2009). The substantial range of physiological, biochemical and psychological targets that one would expect these different treatments to impact speaks to the complexity of pathways and mechanisms that are likely affected in depression.

\section{KETAMINE AND DEPRESSION}

Exciting emerging evidence indicates that the non-competitive $\mathrm{N}$-methyl-D-aspartate (NMDA) glutamate receptor antagonist, ketamine, which is widely used for its anesthetic and analgesic properties, shows promise as a novel treatment for depression. Indeed, a single injection of very low-dose (subanesthetic) ketamine was found not only to promote fast-acting (within hours) antidepressant and anti-suicidal effects but also to be effective in heretofore treatment-resistant patients (Berman et al., 2000; Zarate et al., 2006; Liebrenz et al., 2007; Price et al., 2009; DiazGranados et al., 2010; Ibrahim et al., 2011). Furthermore, the antidepressant effects following a single ketamine dose have been reported to persist for several days to even weeks (Correll and Futter, 2006; Liebrenz et al., 2007; Irwin and Iglewicz, 2010; Mathew et al., 2010). Hence, ketamine is particularly unique in its clinical profile, making it of potentially enormous therapeutic significance. However, the safety of long-term treatment in depressed patients has yet to be fully evaluated, although there are indications that chronic low-dose ketamine may be tolerable, feasible and effective (Liebrenz et al., 2009; aan het Rot et al., 2010; Messer et al., 2010; Murrough et al., 2013). Moreover, despite some important recent advances in our understanding of the various molecular and cellular sequelae following lowdose ketamine treatment (see below), the precise mechanisms underlying ketamine's antidepressant effects are not fully known. Emerging and future studies examining ketamine's mode(s) of action therefore hold the potential to shed much-needed new light on the pathological underpinnings of depression. This, in turn, would be expected to lead to more specific therapeutic targets and the development of safer and more effective drugs. 
The rapid antidepressant response following ketamine treatment, which contrasts sharply with the long antidepressant time lag of several weeks-to-months that is characteristic of traditional monoamine acting drugs (e.g., SSRIs), may at least partially be related to the drug's direct neuronal effects in the PFC and hippocampus (Duman et al., 2012). Consistently, we recently found that a single intraperitoneal injection of racemic ketamine (5 mg/kg), which comprises equal (50:50) concentrations of the (R)- and (S)-enantiomers of ketamine (the latter is roughly 4 times more active, possesses better pharmacokinetic properties and is potentially more tolerable than the former) (Paul et al., 2009; Mion and Villevieille, 2013), altered the levels both of 5HT and its metabolite, 5-HIAA, within the PFC (Clarke and Hayley, unpublished findings). Interestingly, although ketamine increased PFC 5-HT concentrations in the basal state, it prevented the changes in serotonergic neurotransmission following acute restraint stress (Clarke and Hayley, unpublished findings). Others have likewise reported that the antidepressant-like effects of ketamine were dependent upon an intact 5-HT system. Indeed, 5HT depletion using para-chlorophenylalanine blocked the ability of a single injection of ketamine to reduce immobility in a FST (Gigliucci et al., 2013). However, the nature of the behavioral effects of ketamine and the extent of 5-HT involvement in them may vary with a number of factors, including dose, number of treatments and time of testing relative to drug administration. For example, Chindo et al. (2012) found that forced swim immobility was actually enhanced (and not reduced) $24 \mathrm{~h}$ after the final of five daily ketamine injections (30 mg/kg/day). Moreover, the 5-HT acting antidepressant, paroxetine, as well as the atypical antipsychotics, clozapine and risperidone, reversed the ketamineenhanced immobility (Chindo et al., 2012). Although temporal variation in 5-HT functioning could account for the observed differences in forced swim immobility following ketamine treatment, recruitment over time of alternate neurotransmitter systems might also play a role. Indeed, chronic ketamine markedly up-regulated midbrain DA synthesis and levels, together with midbrain BDNF concentrations (Tan et al., 2012). In fact, not only can ketamine influence brain glutamatergic and monaminergic systems (serotonin, DA and NE), but ketamine is also capable of modulating the activity of GABAergic, cholinergic, opioidergic, and even purinergic circuits-albeit at doses considerably higher than those typically employed in the clinical and preclinical depression studies (Mion and Villevieille, 2013).

In addition to alterations of classic neurotransmitter systems, much attention has been afforded the possibility that rapid BDNF changes contribute importantly to the fast-acting antidepressant effects of ketamine (see Figure 1). In this regard, Autry et al. (2011) reported that NMDA receptor blockade by ketamine or MK801 (dizocilpine), which is similar in action to ketamine but who's neurotoxic consequences preclude its use clinically, rapidly increased BDNF levels in mouse hippocampus secondary to the deactivation of eukaryotic elongation factor2 (eEF2) kinase (which normally suppresses the translation of BDNF by phosphorylating eEF2). Furthermore, the swift rise in hippocampal BDNF coincided with reduced immobility in the FST, and conditional BDNF knockout completely abrogated

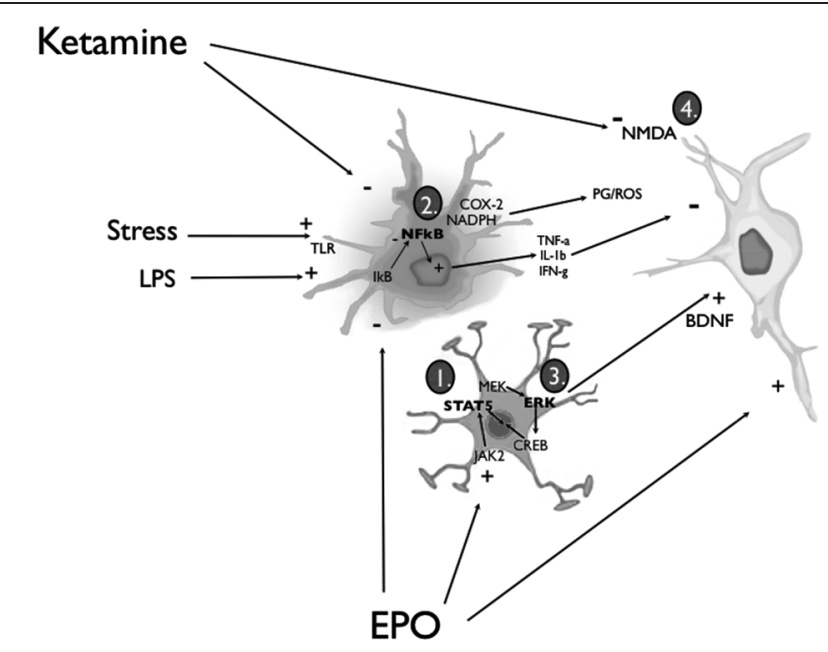

FIGURE 1 | Simplified diagram of the routes through which EPO or ketamine might affect glia and neurons to promote

anti-depressant-like consequences. EPO can act upon astrocytes and neurons by (1) inducing the activation of JAK/STAT and PI3K/Akt signal transduction pathways or (3) promoting MAP kinase-MEK signaling, culminating in extracellular signal-regulated kinase (ERK) phosphorylation and the recruitment of cyclic adenosine monophosphate (CAMP) response element-binding protein (CREB). Engagement of these EPO/EPOR signaling pathways effectively biases the activity of pro- and anti-apoptotic cascades towards the latter, and increases the synthesis and release of BDNF from activated astrocytes and neurons. Signaling in neurons through its TrkB receptors (and the multiple associated signal transduction cascades), BDNF can promote a wide range of neuroplastic changes (e.g., enhanced synthesis of synaptic proteins and neurotrophins) that ultimately favor cell survival. In parallel, EPO can exert anti-inflammatory actions by (2) inhibiting the liberation of nuclear factor $-\mathrm{B}(\mathrm{NF}-\kappa \mathrm{B})$ from its inhibitory binding partner, IkB, in microglial cells. Thus, pro-inflammatory cytokine release (e.g., tumor necrosis factor- $\alpha$ (TNF- $\alpha$ ), IL-1 $\beta$ and IFN- $\gamma$ ), as well as prostaglandin (PG) and reactive oxygen species (ROS) production via COX-2 and NADPH oxidase enzymes is inhibited. EPO can also cross the BBB to directly interact with neuronal receptors. Ketamine was similarly found to be capable of (2) attenuating the activation of microglia and astrocytes, as well as a variety of peripheral immune cells; the end result, once again, is an overall dampening of potentially neurodestructive pro-inflammatory responses. Nonetheless, a majority of the studies investigating the antidepressant-like action of ketamine have focused on the downstream molecular sequelae of the drug's NMDA glutamate receptor antagonism (4). Considered to be of paramount importance in this regard are the up-regulation of BDNF (e.g., via inhibition of eEF2 kinase) and the activation of synaptogenic signaling pathways (i.e., mTOR/p70S6 kinase) (see text for additional details).

ketamine's (as well as MK801's) antidepressant-like behavioral effects (Autry et al., 2011). Similarly, the antidepressant efficacy of ketamine was reduced among depressed patients carrying the loss-of-function BDNF Met66 alleles (compared to the more common $\mathrm{Val} / \mathrm{Val}$ genotype), as well as in stressed rodents bearing the human BDNF Val66Met polymorphism (Laje et al., 2012; Liu et al., 2012). And finally, treatments that enhanced the antidepressant effects of ketamine (e.g., the analgesic agent, tramadol) were also found to rapidly (within $1 \mathrm{~h}$ of treatment) up-regulate hippocampal BDNF, along with its TrkB receptor (Yang et al., 2012). Importantly, then, variation in the speed of 
the neuroplastic responses induced by different treatment modalities may be one potential mechanism accounting for the stark temporal differences in the antidepressant action of ketamine and more conventional antidepressant agents. Indeed, whereas ketamine elevated hippocampal BDNF concentrations within 30 min of administration (Autry et al., 2011), SSRI and tricyclic antidepressants increased central BDNF levels only after several days or weeks of treatment (Martínez-Turrillas et al., 2005; Larsen et al., 2008).

Interestingly, ketamine was also observed to induce robust alterations of PFC synapse structure and function, including enhanced dendritic branching and synaptic receptor number and density (e.g., GluR1-containing AMPA receptors) (Li et al., 2010). These changes, which are consistent with increased synaptogenesis and neuronal synaptic plasticity, followed a rapid time course (within $24 \mathrm{~h}$ of ketamine) only slightly longer than that seen with the BDNF changes. In fact, the neuroplastic effects of ketamine have been posited to stem from the ability of ketamine to expeditiously stimulate the mTOR signaling pathway, most likely via a BDNF-dependent mechanism; the resultant activation of ribosomal p70S6 kinase is considered to drive the rapid protein translation and fast synaptogenic changes that are evident following acute ketamine treatment (Duman et al., 2012). Indeed, Li et al. (2010) demonstrated that the mTOR pathway is rapidly activated following low-dose ketamine, with increases in PFC synaptic signaling proteins (e.g., PSD-95, GluR1) and dendritic spines following shortly after. Moreover, the synaptogenic and antidepressant behavioral effects of ketamine were completely abolished in rats treated with the mTOR inhibitor, rapamycin (Li et al., 2010, 2011). These findings raise the possibility that ketamine could affect mood by rapidly enhancing plastic excitatory transmitter signaling and the processing of BDNF. In fact, a very recent study indicated that, in treatmentresistant depressed patients, acute ketamine augmented plasma BDNF levels and induced electroencephalographic (EEG) changes consistent with enhanced synaptic strength and plasticity (e.g., increased early sleep slow wave activity and high-amplitude waves, increased slow wave slope) (Duncan et al., 2013). Moreover, the BDNF changes varied directly with the EEG parameter changes, and only those individuals positively responding to the ketamine treatment displayed this link (Duncan et al., 2013).

At the same time, SSRI agents too have been associated with synaptic "re-wiring" and "re-modeling". For instance, citalopram partially attenuated the reduction in hippocampal dendritic spine density following dim light-at-night stress in hamsters (Bedrosian et al., 2012), and fluoxetine enhanced dendritic spine density and altered glutamatergic receptor stoichiometry in rat forebrain (Ampuero et al., 2010). Such changes normally are characterized by a substantial time delay and usually coincide with the onset of a positive clinical response (Ampuero et al., 2010). Similarly, the hippocampal volume reductions evident in depressed patients usually normalize after the patients go into remission or at least show substantial improvement (Banasr et al., 2011). Hence, the actual structural brain changes that are induced by the various antidepressant treatments (albeit differentially) might be a crucial common feature in bringing about a positive clinical effect. Indeed, Liu et al. (2012) recently reported that homozygous BDNF Met/Met mice, besides showing a reduced antidepressant response to acute ketamine, were completely insensitive to the PFC synaptogenic effects of the drug.

\section{KETAMINE AND NEUROIMMUNE FACTORS}

Ketamine possesses potent and rapid anti-inflammatory effects that could conceivably be relevant for its antidepressant actions. Numerous studies have demonstrated that ketamine inhibits the production of pro-inflammatory cytokines, including IL- $1 \beta$ and TNF- $\alpha$, as well as the expression of NF- $\kappa$ B (an important inflammatory transcription factor), following immunological challenge with LPS (Takenaka et al., 1994; Sakai et al., 2000; Sun et al., 2004; DeClue et al., 2008). More recent reports have indicated that ketamine, besides reducing the activation of peripheral antigen presenting cells (e.g., macrophages and dendritic cells) and the consequent elaboration of inflammatory mediators, is capable of inhibiting LPS-induced microglial activation, at least in part by negatively regulating MAP kinase activity (Chang et al., 2009; see Figure 1). Consistently, Yang et al. (2013) found that ketamine administration in rats attenuated the LPS-induced rise in PFC IL- 6 and IL- $1 \beta$, as well as the reduction in IL-10; importantly, these immunoregulatory effects coincided with the amelioration of LPS-induced depressive-like behavior in the FST. Additionally, ketamine has been demonstrated to attenuate NF- $\kappa \mathrm{B}$ activation and the expression of the pathogen-associated molecular recognition receptor, Toll like receptor-4 (TLR-4), in astrocytes (Wu et al., 2012). Taken together, these data clearly show that ketamine can influence several aspects of peripheral and central immune signaling, including the initiation of the inflammatory response (e.g., TLR-4), activity and/or levels of downstream effectors (e.g., IL- $1 \beta$ and TNF- $\alpha$ ), and recruitment of intra-cellular messenger pathways (e.g., NF- $\kappa \mathrm{B}$ and MAP kinases). Importantly, each of these immune mechanisms has been implicated in clinical depression and, to some extent, various neurodegenerative conditions.

It has recently been posited that low-grade cerebral inflammation could predispose individuals to depression and suicide by disturbing glutamate neurotransmission (Erhardt et al., 2013). Indeed, increased colony stimulating factor (CSF) levels of the NMDA agonist, quinolinic acid (QUIN), as well as the inflammatory cytokine, IL-6, were reported in suicide victims, and there was a positive correlation between IL-6 and QUIN in suicide attempters (Erhardt et al., 2013). Moreover, an increased density of QUIN-expressing microglia was evident in suicidal individuals (Steiner et al., 2008, 2011). Others have shown that cerebral infections also elevate QUIN together with pro-inflammatory cytokines (Heyes et al., 1995). Thus, ketamine could have beneficial effects in depressed patients, and in particular among individuals who are suicidal or at an increased risk of suicide (e.g., suicide attempt survivors, treatment-resistant patients), by countering the QUIN elevation (via its NMDA antagonism) and, at the same time, inhibiting IL-6 and other inflammatory mediators. In this regard, ketamine completely prevented the hippocampal neuronal damage and neurodegeneration following intracerebroventricular QUIN adminstration in rats (Henschke et al., 1993). 


\section{EMERGING GLUTAMATERGIC MODULATORS AND COMBINATION TREATMENT STRATEGIES}

Despite the mounting evidence indicating that ketamine has rapid and robust antidepressant properties (and notwithstanding the earlier mentioned preliminary clinical data indicating that long-term, low-dose ketamine may be both tolerable and effective; e.g., Messer et al., 2010), concerns over ketamine's psychotomimetic effects have spurred intensive efforts to develop safer and more tolerable glutamate-based antidepressants. At the vanguard of this movement are the "next generation" NMDA receptor antagonists. Included here are the aminoadamantanes, memantine and amantadine (Sani et al., 2012); the NR2Bselective antagonists, traxoprodil (CP-101,606; Preskorn et al., 2008) and MK-0657 (Ibrahim et al., 2012a); and the low-affinity NMDA channel blocker AZD6765 (Zarate et al., 2013). The NMDA receptor glycine-site functional partial agonist, GLYX13 , and its orally bioavailable and presumed more potent analog, NRX-1074, have also garnered the recent attention of researchers and clinicians (Burgdorf et al., 2013; Dolgin, 2013), as have several modulators of metabotropic glutamate receptors (e.g., the mGluR7 allosteric agonist AMN082; Bradley et al., 2012) and select $\alpha$-Amino-3-hydroxy-5-methyl-4-isoxazolepropionic acid (AMPA) receptor potentiators (e.g., Org 26576; Nations et al., 2012). A thorough examination of these up-and-coming glutamatergic modulators falls outside the purview of this review, and we instead refer the interested reader to the excellent recent reviews by Lapidus et al. (2013) and Pilc et al. (2013). Still, it bears mentioning at this juncture that, with the exception of the aminoadamantanes (inconclusive clinical results) and for now NRX-1074 (paucity of published data; Phase I trial underway), very promising preclinical and, where applicable, initial clinical findings have been reported for virtually all of the aforementioned potential new glutamate-based antidepressants.

Even as work is progressing on the development, characterization and testing of these novel glutamatergic agents, optimizing the tolerability and response durability of ketamine-based depression therapies remains an active area of research. In the clinical realm, such efforts have so far been focused largely on identifying add-on or substitution strategies for successfully maintaining the initial rapid antidepressant response induced by ketamine (and thus preventing relapse) (Krystal et al., 2013). Specifically, two small-scale trials have been published to-date examining the efficacy of the glutamatergic modulator, riluzole (which is used to prolong survival in Amytrophic Lateral Sclerosis), in delaying relapse among ketamine-remitted patients with treatmentresistant depression (Mathew et al., 2010; Ibrahim et al., 2012b). Unfortunately, neither of these studies generated positive results; however, as pointed out by Krystal et al. (2013), both trials suffered from a lack of power.

Also garnering recent research and clinical attention has been the idea that combined treatment with ketamine and ECT might result in synergistic enhancements of mood in patients with severe and intractable depression symptoms. Unlike the ketamine-plusriluzole maintenance therapy trials, this area of research-which was spurred on by a couple of promising case reports (reviewed in Loo et al. (2010)) - is concerned not so much with extending the antidepressant effect of ketamine but rather exploring the potential of low-dose ketamine to augment ECT. While the handful of prospective and retrospective clinical studies that have since been published on the subject- their methodological differences notwithstanding - have tended to produce positive results (Okamoto et al., 2010; Kranaster et al., 2011; Loo et al., 2012; Wang et al., 2012), the findings are by no means definitive (e.g., Abdallah et al., 2012; Järventausta et al., 2013) and more testing and optimizing of combined ketamine and ECT in depression is clearly in order.

Apart from these burgeoning clinical efforts, numerous preclinical infrahuman investigations have provided support for the idea that sub-threshold doses of ketamine (with respect to treating depressive-like pathology) could be combined with down-titrated doses of other putative antidepressant agents to promote robust antidepressant-like outcomes, without the attendant psychotomimetic concerns. For instance, it has been more than 10 years since Chaturvedi et al. $(1999,2001)$ first demonstrated that ketamine displayed antidepressant-like synergism with fluvoxamine and imipramine in the rodent FST. The latter effect was recently recapitulated by Réus et al. (2011), who further showed that combined ketamine-plusimipramine resulted in a significantly more robust increase of hippocampal, PFC and amygdalar CREB and BDNF levels than each treatment alone. Similarly, combinations of subthreshold doses of ketamine and lithium synergistically reduced immobility in the rodent FST (Ghasemi et al., 2010; Liu et al., 2013) and enhanced structural and functional neuroplastic changes in the PFC (increased mTOR signaling, dendritic spine density and diameter, and excitatory postsynaptic currents; Liu et al., 2013). Potentiation of ketamine-induced antidepressant-like effects has also been reported with analgesic and anesthetic agents, wherein facilitation of neurotrophin (Yang et al., 2012) and AMPA receptor-mediated signaling Wang et al. (2011b) were found to be of vital importance. Moreover, Akinfiresoye and Tizabi (2013) observed that repeated exposures to a combination of ketamine and AMPA, at doses that were ineffective on their own, induced marked synaptogenic and antidepressant-like effects (increased p-mTOR, synapsin1 and BDNF; decreased FST immobility). While these preclinical findings have yet to be translated into the clinical realm, it is tempting to at least speculate on the potential role of low-dose "ketamine-plus" combination therapies in depression.

\section{ERYTHROPOIETIN (EPO)}

Emerging data, albeit relatively scant, indicate that EPO too has the potential to improve the cognitive and emotional symptoms of major depression. In fact, a recent review of the EPO literature demonstrated that four out of an existing five stressorbased animal studies and all seven of the extant human studies (in depressed and non-depressed subjects alike) demonstrated positive effects of EPO with respect to hippocampaldependent memory and emotion-related behavior (Miskowiak et al., 2012).

EPO is a cytokine that is produced predominately by the kidney. Besides directing the trafficking of immune cells and having anti-apoptotic actions, EPO was recently reported to 
induce antidepressant-like effects in the forced swim and noveltyinduced hypophagia tests (Girgenti et al., 2009). EPO and its receptors (EPOR) are expressed centrally throughout the lifespan, but are particularly abundant in the developing and ageing brain (Sanchez et al., 2009). Moreover, within the hypothalamus, hippocampus and neocortex of normally developing rats, EPO and/or EPOR immunoreactivity was localized primarily to neurons (and not astrocytes or microglia) (Sanchez et al., 2009). Similarly, EPO and EPOR were detected in adult midbrain DA and cortical neurons, as well as cultured cortical and cerebellular neurons (Csete et al., 2004). Yet, astrocytes, microglia and endothelial cells have also been found to express EPO and its receptor, especially following injury or neurodegeneration (Bernaudin et al., 1999; Assaraf et al., 2007; Nadam et al., 2007). Taken together with the fact that the non-hematopoietic carbamylated form of EPO, c-EPO, also has robust CNS effects (Leconte et al., 2011; Ding et al., 2013), it is obvious that EPO has important central effects independent of its impact on red blood cells. Perhaps most importantly with regards to depression and other stress-related disorders, EPO was reported to induce BDNF expression and have potent neuroplastic effects (Leconte et al., 2011; Mengozzi et al., 2012).

As already mentioned, augmented BDNF signaling has been strongly linked to antidepressant outcomes; however, a complication of using BDNF itself clinically is that the neurotrophin does not appreciably cross the blood brain barrier (BBB; Pardridge et al., 1994). BDNF treatment may also be associated with substantial side effects, including those related to pain pathways (Pezet and McMahon, 2006). In contrast, EPO is routinely and safely used to treat anemia (Sargin et al., 2010) and is considered to readily cross the BBB (Brines et al., 2000). While it is true that a few studies failed to detect increased EPO CSF levels with systemic administration (Juul et al., 1997, 1999), others reliably found EPO to be elevated in the CSF of humans and animals after therapeutic systemic doses (Alafaci et al., 2000; Ehrenreich et al., 2002). Indeed, both the murine and human forms of EPO, as well as the human analog often used clinically, decarbepoetin- $\alpha$, all crossed the BBB in untreated naïve mice and accumulated at clinically significant concentrations (Banks et al., 2004).

Given the data implicating hippocampal disturbances in depression, it is particularly significant that EPO protects hippocampal neurons from stressor-induced apoptosis (Kumral et al., 2005; Zhang et al., 2007) and increases adult hippocampal neurogenesis (Wang et al., 2004; Chen et al., 2007; Leconte et al., 2011). At the same time, in rodents, EPO was reported to improve spatial memory in the Morris water maze (Hengemihle et al., 1996; Zhang et al., 2009) and to prevent ischemia-induced cognitive impairments in a passive avoidance task (Sakanaka et al., 1998). Similarly, EPO promoted improved cognitive functioning in MS patients (Ehrenreich et al., 2007a) and among individuals with schizophrenia (Ehrenreich et al., 2007b). Thus, it would appear that EPO has potent cognitive-enhancing actions which seem likely to be at least partially related to the trophic cytokine's hippocampal neuroplastic effects. Interestingly, recent pre-clinical data also suggest that EPO may hold promise as an agent to promote neuronal recovery. In fact, as pointed out by Sargin et al. (2010), neuroprotective outcomes have been reported in an exceedingly large majority of the nearly 200 studies using EPO in animal models of stroke and traumatic brain injury.

\section{EPO SIGNALING AND DEPRESSION}

Although little evidence to date indicates that central EPO signaling is affected by antidepressant medicines, Girgenti et al. (2009) found that EPO levels were elevated in the hippocampal dentate gyrus after electroconvulsive seizure in rats. As well, in human imaging studies, EPO modulated brain responses to emotional information in both healthy volunteers and depressed patients (Miskowiak et al., 2007, 2009, 2010), just as conventional SSRIs were reported to do (Harmer et al., 2006; Murphy et al., 2009). Similarly, we recently found that systemic EPO treatment had antidepressant-like effects in the FST and blunted the impact of stressor exposure on exploration in open field and elevated plus maze paradigms (Osborn et al., 2013). And consistent with the aforementioned earlier reports documenting the neurogenic potential of EPO (e.g., Leconte et al., 2011), in our hands the hematopoietic growth factor significantly increased hippocampal neurogenesis, and this effect was apparent in naïve and stressed mice alike (Osborn et al., 2013).

As in the case of ketamine, it is critically important to understand the signaling mechanisms through which EPO could impart its antidepressant effects. Briefly, EPO binding promotes the homodimerization of two EPOR molecules, leading to a conformational change that induces the phosphorylation of the receptor-associated Janus kinase-2 (JAK2) protein tyrosine kinase and subsequent activation of intermediate intracellular factors; these include phosphatidylinositide 3-kinase (PI3-K), Akt/protein kinase-B, mitogen-activated protein kinases (MAPKs), and signal transducer and activator of transcription-5 (STAT5; Broxmeyer, 2013; see Figure 1). In non-erythroid cells, EPO acts through a receptor that is also linked to CD131, the common beta chain receptor subunit through which granulocyte-macrophage colony stimulating factor (GM-CSF) also signals (Broxmeyer, 2013). This receptor complex is expressed both by neurons and immune cells, and its stimulation induces STAT5 along with c-Jun Nterminal kinase (JNK), PI3K and MAPK (Brines and Cerami, 2008). Importantly, these signaling cascades have all been linked to the activation of anti-apoptotic factors, cell differentiation, cellular growth, and the modulation of plasticity. For instance, Byts et al. (2008) reported that the induction of STAT5 and Akt in hippocampal neurons was essential for the neurotrophic effects of EPO.

Recent data pointing to a connection between EPO and BDNF may be particularly telling of the mechanisms subserving the potential antidepressant action of EPO. Several reports have indicated that EPO can increase BDNF levels and synthesis (Wang et al., 2004; Girgenti et al., 2009; Mengozzi et al., 2012); this of course contrasts with the known BDNF-antagonizing effects of stressors. It is thus tempting to speculate that an initial EPOinduced rise in BDNF could synergize with further exogenously applied EPO to reinforce specific molecular and cellular mechanisms of antidepressant action. This possibility holds for the prospective combination of $\mathrm{EPO}$ with any number of established BDNF-stimulating treatments (e.g., SSRIs, ketamine, and even 
exercise). Indeed, BDNF and EPO share common intra-cellular signaling pathways, including the PI3-K and MAP kinase cascades. There is, therefore, ample opportunity for the convergence of EPO and BDNF signaling, and studies are definitely warranted to flesh out this possibility (Figure 1).

In contrast to the positive interactions observed between BDNF and EPO, pro-inflammatory stimuli generally act to downregulate EPO. Indeed, LPS, as well as IL- $1 \beta$ and TNF- $\alpha$, were demonstrated to reduce circulatory EPO mRNA and protein levels through mechanisms dependent on NF- $\kappa$ B activation (Nairz et al., 2012). Conversely, EPO itself appears to have potent antiinflammatory properties, as evidenced by its successful application in a number of chronic inflammatory conditions and/or their animal models (e.g., colitis, MS and diabetes) (Yuan et al., 2008; Nairz et al., 2011; Meng et al., 2013). Likewise, EPO was shown to attenuate or prevent a broad range of central and peripheral pathology following LPS exposure, including lung and brain injury, renal dysfunction, and vascular hypo-reactivity (Kumral et al., 2007; Mitra et al., 2007; di Villa Bianca et al., 2009; Shang et al., 2009); however, several conflicting reports do exist (e.g., Wilms et al., 2009; Wu et al., 2010).

Although very few studies have explicitly investigated how EPO might promote anti-inflammatory responses, a recent report suggests that inhibition of the NF- $\kappa \mathrm{B}$ p 65 subunit is likely to be essential (Nairz et al., 2011). Importantly, NF- $\kappa \mathrm{B}$ signaling is considered the primary pathway mediating the effects of IL$1 \beta$ and TNF- $\alpha$ on immune and neural cells (Kataoka, 2009), and a recent study implicated $\mathrm{NF}-\kappa \mathrm{B}$ as a vital contributor to the anti-neurogenic and depressive-like behavioral consequences of chronic mild stress (Koo et al., 2010). These data raise the intriguing possibility that EPO could impart antidepressant-like effects not only through the stimulation of trophic and neuroplastic processes but also by modulating the inflammatory milieu (by way of restraining inflammatory NF- $\kappa \mathrm{B}$ signaling) that is both evident and pathologically relevant in many stressor-related disorders.

\section{CONCLUSIONS}

In many cases, the current most efficacious treatment involves the combined administration of more than one antidepressant or other compounds, possibly by promoting synergistic neuronal effects. This reinforces the view that depression involves a spectrum of varied symptoms and likely various etiological mechanisms are involved. In this regard, we posit that stress and dysregulated immune factors acting against a backdrop of genetic vulnerability ultimately shape the evolution of depression by affecting classic neurotransmitter and peptide circuits, as well as interfering with neuroplastic processes.

A sizable proportion of individuals are either totally unresponsive or partially responsive to existing antidepressant treatments. Moreover, patients that do respond positively to antidepressants typically show only partial symptom remission and often relapse after treatment discontinuation, promoting the view that depression is a lifelong condition. The chronic course for the illness suggests that depression could involve persistent neural changes stemming from disturbances of neuroplasticity. Hence, novel strategies that directly target such disturbances, rather than simply managing downstream neurotransmitters, are urgently required.

Novel treatments include the NMDA antagonist, ketamine, which promotes unusually rapid and sustained antidepressant responses after a single administration. Importantly, such effects have been linked to rapid neuroplastic events, including synaptogenesis; yet, the drug also has effects on multiple neurotransmitter systems and influences immune factors. Other potential emerging treatments include cytokines with trophic properties, such as EPO. Indeed, through its effects on BDNF, immune and neuroplastic processes, EPO holds tremendous possibility as an adjunct treatment that could be co-administered with an SSRI or other standard antidepressant agent. In effect, future pharmacogenic approaches might be utilized to tailor specific treatment combinations to specific individuals with certain genetic polymorphisms and life stressor histories. However, whatever the case may be, we believe that all such treatments will exert and/or maintain positive clinical outcomes, at least in part, by affecting the plasticity of emotional circuits.

\section{REFERENCES}

aan het Rot, M., Collins, K. A., Murrough, J. W., Perez, A. M., Reich, D. L., Charney, D. S., et al. (2010). Safety and efficacy of repeated-dose intravenous ketamine for treatment-resistant depression. Biol. Psychiatry 67, 139-145. doi: 10.1016/j. biopsych.2009.08.038

Abdallah, C. G., Fasula, M., Kelmendi, B., Sanacora, G., and Ostroff, R. (2012). Rapid antidepressant effect of ketamine in the electroconvulsive therapy setting. J. ECT 28, 157-161. doi: 10.1097/YCT.0b013e31824f8296

Akinfiresoye, L., and Tizabi, Y. (2013). Antidepressant effects of AMPA and ketamine combination: role of hippocampal BDNF, synapsin, and mTOR. Psychopharmacology (Berl) doi: 10.1007/s00213-013-3153-2. [Epub ahead of print].

Alafaci, C., Salpietro, F., Grasso, G., Sfacteria, A., Passalacqua, M., Morabito, A., et al. (2000). Effect of recombinant human erythropoietin on cerebral ischemia following experimental subarachnoid hemorrhage. Eur. J. Pharmacol. 406, 219 225. doi: 10.1016/s0014-2999(00)00691-9

Alboni, S., Benatti, C., Capone, G., Corsini, D., Caggia, F., Tascedda, F., et al. (2010). Time-dependent effects of escitalopram on brain derived neurotrophic factor (BDNF) and neuroplasticity related targets in the central nervous system of rats. Eur. J. Pharmacol. 643, 180-187. doi: 10.1016/j.ejphar.2010.06.028

Ampuero, E., Rubio, F. J., Falcon, R., Sandoval, M., Diaz-Veliz, G., Gonzalez, R. E., et al. (2010). Chronic fluoxetine treatment induces structural plasticity and selective changes in glutamate receptor subunits in the rat cerebral cortex. Neuroscience 169, 98-108. doi: 10.1016/j.neuroscience.2010.04.035

Angelucci, F., Aloe, L., Jiménez-Vasquez, P., and Mathé, A. A. (2003). Lithium treatment alters brain concentrations of nerve growth factor, brain-derived neurotrophic factor and glial cell line-derived neurotrophic factor in a rat model of depression. Int. J. Neuropsychopharmacol. 6, 225-231. doi: 10. $1017 /$ s1461145703003468

Anisman, H., Merali, Z., and Hayley, S. (2008). Neurotransmitter, peptide and cytokine processes in relation to depressive disorder: comorbidity between depression and neurodegenerative disorders. Prog. Neurobiol. 85, 1-74. doi: 10. 1016/j.pneurobio.2008.01.004

Arnone, D., McKie, S., Elliott, R., Juhasz, G., Thomas, E. J., Downey, D., et al. (2012). State-dependent changes in hippocampal grey matter in depression. Mol. Psychiatry doi: 10.1038/mp.2012.150. [Epub ahead of print].

Assaraf, M. I., Diaz, Z., Liberman, A., Miller, Jr. W. H., Arvanitakis, Z., Li, Y., et al. (2007). Brain erythropoietin receptor expression in Alzheimer disease and mild cognitive impairment. J. Neuropathol. Exp. Neurol. 66, 389-398. doi: 10. 1097/nen.0b013e3180517b28

Autry, A. E., Adachi, M., Nosyreva, E., Na, E. S., Los, M. F., Cheng, P. F., et al. (2011) NMDA receptor blockade at rest triggers rapid behavioural antidepressant responses. Nature 475, 91-95. doi: 10.1038/nature10130

Balu, D. T., Hoshaw, B. A., Malberg, J. E., Rosenzweig-Lipson, S., Schechter, L. E., and Lucki, I. (2008). Differential regulation of central BDNF protein levels by 
antidepressant and non-antidepressant drug treatments. Brain Res. 1211, 37-43. doi: 10.1016/j.brainres.2008.03.023

Banasr, M., Chowdhury, G. M., Terwilliger, R., Newton, S. S., Duman, R. S., Behar, K. L., et al. (2010). Glial pathology in an animal model of depression: reversal of stress-induced cellular, metabolic and behavioral deficits by the glutamatemodulating drug riluzole. Mol. Psychiatry 15, 501-511. doi: 10.1038/mp.2008. 106

Banasr, M., Dwyer, J. M., and Duman, R. S. (2011). Cell atrophy and loss in depression: reversal by antidepressant treatment. Curr. Opin. Cell Biol. 23, 730737. doi: 10.1016/j.ceb.2011.09.002

Banks, W. A., Jumbe, N. L., Farrell, C. L., Niehoff, M. L., and Heatherington, A. C. (2004). Passage of erythropoietic agents across the blood-brain barrier: a comparison of human and murine erythropoietin and the analog darbepoetin alfa. Eur. J. Pharmacol. 505, 93-101. doi: 10.1016/j.ejphar.2004. 10.035

Bauer, M., Pfennig, A., Severus, E., Whybrow, P. C., Angst, J., and Möller, H. J.; on behalf of the Task Force on Unipolar Depressive Disorders. (2013). World Federation of Societies of Biological Psychiatry (WFSBP) guidelines for biological treatment of unipolar depressive disorders, Part 1: Update 2013 on the acute and continuation treatment of unipolar depressive disorders. World J. Biol. Psychiatry 14, 334-385. doi: 10.3109/15622975.2013. 804195

Beauregard, M. (2009). Effect of mind on brain activity: evidence from neuroimaging studies of psychotherapy and placebo effect. Nord. J. Psychiatry 63, 5-16. doi: $10.1080 / 08039480802421182$

Bedrosian, T. A., Weil, Z. M., and Nelson, R. J. (2012). Chronic citalopram treatment ameliorates depressive behavior associated with light at night. Behav. Neurosci. 126, 654-658. doi: 10.1037/a0029699

Berman, R. M., Cappiello, A., Anand, A., Oren, D. A., Heninger, G. R., Charney, D. S., et al. (2000). Antidepressant effects of ketamine in depressed patients. Biol. Psychiatry 47, 351-354. doi: 10.1016/s0006-3223(99)00230-9

Bernaudin, M., Marti, H. H., Roussel, S., Divoux, D., Nouvelot, A., MacKenzie, E. T., et al. (1999). A potential role for erythropoietin in focal permanent cerebral ischemia in mice. J. Cereb. Blood Flow Metab. 19, 643-651. doi: 10. 1097/00004647-199906000-00007

Blier, P., and Blondeau, C. (2011). Neurobiological bases and clinical aspects of the use of aripiprazole in treatment-resistant major depressive disorder. J. Affect. Disord. 128(Suppl. 1), S3-S10. doi: 10.1016/s0165-0327(11) 70003-9

Blier, P., Gobbi, G., Turcotte, J. E., de Montigny, C., Boucher, N., Hébert, C., et al. (2009). Mirtazapine and paroxetine in major depression: a comparison of monotherapy versus their combination from treatment initiation. Eur. Neuropsychopharmacol. 19, 457-465. doi: 10.1016/j.euroneuro.2009. 01.015

Blier, P., Ward, H. E., Tremblay, P., Laberge, L., Hébert, C., and Bergeron, R. (2010). Combination of antidepressant medications from treatment initiation for major depressive disorder: a double-blind randomized study. Am. J. Psychiatry 167, 281-288. doi: 10.1176/appi.ajp.2009.09020186

Boldrini, M., Underwood, M. D., Hen, R., Rosoklija, G. B., Dwork, A. J., John Mann, J., et al. (2009). Antidepressants increase neural progenitor cells in the human hippocampus. Neuropsychopharmacology 34, 2376-2389. doi: 10. 1038/npp. 2009.75

Bradley, S. R., Uslaner, J. M., Flick, R. B., Lee, A., Groover, K. M., and Hutson, P. H. (2012). The mGluR7 allosteric agonist AMN082 produces antidepressant-like effects by modulating glutamatergic signaling. Pharmacol. Biochem. Behav. 101, 35-40. doi: 10.1016/j.pbb.2011.11.006

Bremner, J. D., Narayan, M., Anderson, E. R., Staib, L. H., Miller, H. L., and Charney, D. S. (2000). Hippocampal volume reduction in major depression. Am. J. Psychiatry 157, 115-118.

Brines, M., and Cerami, A. (2008). Erythropoietin-mediated tissue protection: reducing collateral damage from the primary injury response. J. Intern. Med. 264, 405-432. doi: 10.1111/j.1365-2796.2008.02024.x

Brines, M. L., Ghezzi, P., Keenan, S., Agnello, D., de Lanerolle, N. C., Cerami, C., et al. (2000). Erythropoietin crosses the blood-brain barrier to protect against experimental brain injury. Proc. Natl. Acad. Sci. U S A 97, 10526-10531. doi: 10. 1073/pnas.97.19.10526

Broxmeyer, H. E. (2013). Erythropoietin: multiple targets, actions, and modifying influences for biological and clinical consideration. J. Exp. Med. 210, 205-208. doi: $10.1084 /$ jem.20122760
Buchheim, A., Viviani, R., Kessler, H., Kächele, H., Cierpka, M., Roth, G., et al. (2012). Changes in prefrontal-limbic function in major depression after 15 months of long-term psychotherapy. PLoS One 7:e33745. doi: 10.1371/journal. pone. 0033745

Burgdorf, J., Zhang, X. L., Nicholson, K. L., Balster, R. L., Leander, J. D., Stanton, P. K., et al. (2013). GLYX-13, a NMDA receptor glycine-site functional partial agonist, induces antidepressant-like effects without ketamine-like side effects. Neuropsychopharmacology 38, 729-742. doi: 10.1038/npp.2012.246

Byts, N., Samoylenko, A., Fasshauer, T., Ivanisevic, M., Hennighausen, L., Ehrenreich, H., et al. (2008). Essential role for Stat5 in the neurotrophic but not in the neuroprotective effect of erythropoietin. Cell Death Differ. 15, 783-792. doi: $10.1038 /$ cdd.2008.1

Carballedo, A., Scheuerecker, J., Meisenzahl, E., Schoepf, V., Bokde, A., Möller, H. J., et al. (2011). Functional connectivity of emotional processing in depression. J. Affect. Disord. 134, 272-279. doi: 10.1016/j.jad.2011.06.021

Castrén, E., and Rantamäki, T. (2010). The role of BDNF and its receptors in depression and antidepressant drug action: reactivation of developmental plasticity. Dev. Neurobiol. 70, 289-297. doi: 10.1002/dneu.20758

Castrén, E., Võikar, V., and Rantamäki, T. (2007). Role of neurotrophic factors in depression. Curr. Opin. Pharmacol. 7, 18-21. doi: 10.1016/j.coph.2006.08.009

Cattaneo, A., Bocchio-Chiavetto, L., Zanardini, R., Milanesi, E., Placentino, A., and Gennarelli, M. (2010). Reduced peripheral brain-derived neurotrophic factor mRNA levels are normalized by antidepressant treatment. Int. J. Neuropsychopharmacol. 13, 103-108. doi: 10.1017/s1461145709990812

Chang, Y., Lee, J. J., Hsieh, C. Y., Hsiao, G., Chou, D. S., and Sheu, J. R. (2009). Inhibitory effects of ketamine on lipopolysaccharide-induced microglial activation. Mediators Inflamm. 2009:705379. doi: 10.1155/2009/705379

Chaturvedi, H. K., Chandra, D., and Bapna, J. S. (1999). Interaction between $\mathrm{N}$-methyl-D-aspartate receptor antagonists and imipramine in shock-induced depression. Indian J. Exp. Biol. 37, 952-958.

Chaturvedi, H. K., Bapna, J. S., and Chandra, D. (2001). Effect of fluvoxamine and N-methyl-D-aspartate receptor antagonists on shock-induced depression in mice. Indian J. Physiol. Pharmacol. 45, 199-207.

Chen, Y., Ai, Y., Slevin, J. R., Maley, B. E., and Gash, D. M. (2005). Progenitor proliferation in the adult hippocampus and substantia nigra induced by glial cell line-derived neurotrophic factor. Exp. Neurol. 196, 87-95. doi: 10.1016/j. expneurol.2005.07.010

Chen, Z. Y., Asavaritikrai, P., Prchal, J. T., and Noguchi, C. T. (2007). Endogenous erythropoietin signaling is required for normal neural progenitor cell proliferation. J. Biol. Chem. 282, 25875-25883. doi: 10.1074/jbc.m701988200

Chen, J., Gao, K., and Kemp, D. E. (2011). Second-generation antipsychotics in major depressive disorder: update and clinical perspective. Curr. Opin. Psychiatry 24, 10-17. doi: 10.1097/yco.0b013e3283413505

Cheng, Y. Q., Xu, J., Chai, P., Li, H. J., Luo, C. R., Yang, T., et al. (2010). Brain volume alteration and the correlations with the clinical characteristics in drugnaïve first-episode MDD patients: a voxel-based morphometry study. Neurosci. Lett. 480, 30-34. doi: 10.1016/j.neulet.2010.05.075

Chindo, B. A., Adzu, B., Yahaya, T. A., and Gamaniel, K. S. (2012). Ketamineenhanced immobility in forced swim test: a possible animal model for the negative symptoms of schizophrenia. Prog. Neuropsychopharmacol. Biol. Psychiatry 38, 310-316. doi: 10.1016/j.pnpbp.2012.04.018

Colla, M., Kronenberg, G., Deuschle, M., Meichel, K., Hagen, T., Bohrer, M., et al. (2007). Hippocampal volume reduction and HPA-system activity in major depression. J. Psychiatr. Res. 41, 553-560. doi: 10.1016/j.jpsychires.2006.06.011

Correll, G. E., and Futter, G. E. (2006). Two case studies of patients with major depressive disorder given low-dose (subanesthetic) ketamine infusions. Pain Med. 7, 92-95. doi: 10.1111/j.1526-4637.2006.00101.x

Cox, G. R., Callahan, P., Churchill, R., Hunot, V., Merry, S. N., Parker, A. G., et al. (2012). Psychological therapies versus antidepressant medication, alone and in combination for depression in children and adolescents. Cochrane Database Syst. Rev. 11:CD008324. doi: 10.1002/14651858.cd008324

Csete, M., Rodriguez, L., Wilcox, M., and Chadalavada, S. (2004). Erythropoietin receptor is expressed on adult rat dopaminergic neurons and erythropoietin is neurotrophic in cultured dopaminergic neuroblasts. Neurosci. Lett. 359, 124126. doi: $10.1016 /$ j.neulet.2004.01.068

Cuijpers, P., Reynolds, C. F. 3rd, Donker, T., Li, J., Andersson, G., and Beekman, A. (2012). Personalized treatment of adult depression: medication, psychotherapy, or both? A systematic review. Depress. Anxiety 29, 855-864. doi: 10.1002/da. 21985 
DeClue, A. E., Cohn, L. A., Lechner, E. S., Bryan, M. E., and Dodam, J. R. (2008). Effects of subanesthetic doses of ketamine on hemodynamic and immunologic variables in dogs with experimentally induced endotoxemia. Am. J. Vet. Res. 69, 228-232. doi: 10.2460/ajvr.69.2.228

Dedoni, S., Olianas, M. C., Ingianni, A., and Onali, P. (2012). Type I interferons impair BDNF-induced cell signaling and neurotrophic activity in differentiated human SH-SY5Y neuroblastoma cells and mouse primary cortical neurons. J. Neurochem. 122, 58-71. doi: 10.1111/j.1471-4159.2012.07766.x

de Maat, S. M., Dekker, J., Schoevers, R. A., and de Jonghe, F. (2007). Relative efficacy of psychotherapy and combined therapy in the treatment of depression: a meta-analysis. Eur. Psychiatry 22, 1-8. doi: 10.1016/j.eurpsy.2006.10.008

DiazGranados, N., Ibrahim, L. A., Brutsche, N. E., Ameli, R., Henter, I. D., Luckenbaugh, D. A., et al. (2010). Rapid resolution of suicidal ideation after a single infusion of an N-methyl-D-aspartate antagonist in patients with treatment-resistant major depressive disorder. J. Clin. Psychiatry 71, 1605-1611. doi: 10.4088/jcp.09m05327blu

Di Benedetto, B., Kühn, R., Nothdurfter, C., Rein, T., Wurst, W., and Rupprecht, R. (2012). N-desalkylquetiapine activates ERK1/2 to induce GDNF release in C6 glioma cells: a putative cellular mechanism for quetiapine as antidepressant. Neuropharmacology 62, 209-216. doi: 10.1016/j.neuropharm.2011.07.001

di Villa Bianca, Rd., Sorrentino, R., Mitidieri, E., Marzocco, S., Autore, G., Thiemermann, C., et al. (2009). Recombinant human erythropoietin prevents lipopolysaccharide-induced vascular hyporeactivity in the rat. Shock 31, 529534. doi: 10.1097/shk.0b013e31818909c0

Ding, J., Li, Q. Y., Yu, J. Z., Wang, X., Lu, C. Z., Ma, C. G., et al. (2013). Carbamylated erythropoietin ameliorates hypoxia-induced cognitive and behavioral defects with the generation of choline acetyltransferase-positive neurons. J. Neurosci. Res. 91, 73-82. doi: 10.1002/jnr.23124

Diniz, L., dos Santos, T. B., Britto, L. R., Céspedes, I. C., Garcia, M. C., SpadariBratfisch, R. C., et al. (2013). Effects of chronic treatment with corticosterone and imipramine on fos immunoreactivity and adult hippocampal neurogenesis. Behav. Brain Res. 238, 170-177. doi: 10.1016/j.bbr.2012.10.024

Diniz, B. S., Teixeira, A. L., Miranda, A. S., Talib, L. L., Gattaz, W. F., and Forlenza, O. V. (2012). Circulating Glial-derived neurotrophic factor is reduced in late-life depression. J. Psychiatr. Res. 46, 135-139. doi: 10.1016/j.jpsychires.2011.09.007

Dolgin, E. (2013). Rapid antidepressant effects of ketamine ignite drug discovery. Nat. Med. 19, 8. doi: 10.1038/nm0113-8

Drevets, W. C., Price, J. L., and Furey, M. L. (2008). Brain structural and functional abnormalities in mood disorders: implications for neurocircuitry models of depression. Brain Struct. Funct. 213, 93-118. doi: 10.1007/s00429-008-0189-x

Duman, R. S., Li, N., Liu, R. J., Duric, V., and Aghajanian, G. (2012). Signaling pathways underlying the rapid antidepressant actions of ketamine. Neuropharmacology 62, 35-41. doi: 10.1016/j.neuropharm.2011.08.044

Duncan, W. C., Sarasso, S., Ferrarelli, F., Selter, J., Riedner, B. A., Hejazi, N. S., et al. (2013). Concomitant BDNF and sleep slow wave changes indicate ketamineinduced plasticity in major depressive disorder. Int. J. Neuropsychopharmacol. 16, 301-311. doi: 10.1017/s1461145712000545

Ehrenreich, H., Fischer, B., Norra, C., Schellenberger, F., Stender, N., Stiefel, M., et al. (2007b). Exploring recombinant human erythropoietin in chronic progressive multiple sclerosis. Brain 130, 2577-2588. doi: 10.1093/brain/awm203

Ehrenreich, H., Hasselblatt, M., Dembowski, C., Cepek, L., Lewczuk, P., Stiefel, M., et al. (2002). Erythropoietin therapy for acute stroke is both safe and beneficial. Mol. Med. 8, 495-505.

Ehrenreich, H., Hinze-Selch, D., Stawicki, S., Aust, C., Knolle-Veentjer, S., Wilms, S., et al. (2007a). Improvement of cognitive functions in chronic schizophrenic patients by recombinant human erythropoietin. Mol. Psychiatry 12, 206-220. doi: 10.1038/sj.mp.4001907

Eisch, A. J., Bolaños, C. A., de Wit, J., Simonak, R. D., Pudiak, C. M., Barrot, M., et al. (2003). Brain-derived neurotrophic factor in the ventral midbrain-nucleus accumbens pathway: a role in depression. Biol. Psychiatry 54, 994-1005. doi: 10. 1016/j.biopsych.2003.08.003

El Mansari, M., Guiard, B. P., Chernoloz, O., Ghanbari, R., Katz, N., and Blier, P. (2010). Relevance of norepinephrine-dopamine interactions in the treatment of major depressive disorder. CNS Neurosci. Ther. 16, e1-e17. doi: 10.1111/j.17555949.2010.00146.x

Encinas, J. M., Hamani, C., Lozano, A. M., and Enikolopov, G. (2011). Neurogenic hippocampal targets of deep brain stimulation. J. Comp. Neurol. 519, 6-20. doi: $10.1002 /$ cne. 22503
Erhardt, S., Lim, C. K., Linderholm, K. R., Janelidze, S., Lindqvist, D., Samuelsson, M., et al. (2013). Connecting inflammation with glutamate agonism in suicidality. Neuropsychopharmacology 38, 743-752. doi: 10.1038/npp. 2012.248

Ernst, C., Olson, A. K., Pinel, J. P., Lam, R. W., and Christie, B. R. (2006). Antidepressant effects of exercise: evidence for an adult-neurogenesis hypothesis? J. Psychiatry Neurosci. 31, 84-92.

Ghasemi, M., Raza, M., and Dehpour, A. R. (2010). NMDA receptor antagonists augment antidepressant-like effects of lithium in the mouse forced swimming test. J. Psychopharmacol. 24, 585-594. doi: 10.1177/0269881109104845

Gibney, S. M., McGuinness, B., Prendergast, C., Harkin, A., and Connor, T. J. (2013). Poly I:C-induced activation of the immune response is accompanied by depression and anxiety-like behaviours, kynurenine pathway activation and reduced BDNF expression. Brain Behav. Immun. 28, 170-181. doi: 10.1016/j.bbi. 2012.11.010

Gigliucci, V., O’Dowd, G., Casey, S., Egan, D., Gibney, S., and Harkin, A. (2013). Ketamine elicits sustained antidepressant-like activity via a serotonin-dependent mechanism. Psychopharmacology (Berl) 228, 157-166. doi: 10.1007/s00213-0133024-X

Girgenti, M. J., Hunsberger, J., Duman, C. H., Sathyanesan, M., Terwilliger, R., and Newton, S. S. (2009). Erythropoietin induction by electroconvulsive seizure, gene regulation, and antidepressant-like behavioral effects. Biol. Psychiatry 66, 267-274. doi: 10.1016/j.biopsych.2008.12.005

Gittins, R. A., and Harrison, P. J. (2011). A morphometric study of glia and neurons in the anterior cingulate cortex in mood disorder. J. Affect. Disord. 133, 328-332. doi: 10.1016/j.jad.2011.03.042

Goedert, M., Spillantini, M. G., Del Tredici, K., and Braak, H. (2013). 100 years of Lewy pathology. Nat. Rev. Neurol. 9, 13-24. doi: 10.1038/nrneurol.2012.242

Golan, M., Schreiber, G., and Avissar, S. (2011). Antidepressants elevate GDNF expression and release from $\mathrm{C}_{6}$ glioma cells in a $\beta$-arrestin1-dependent, CREB interactive pathway. Int. J. Neuropsychopharmacol. 14, 1289-1300. doi: 10. 1017/S1461145710001550

Goodwin, G., Fleischhacker, W., Arango, C., Baumann, P., Davidson, M., de Hert, M., et al. (2009). Advantages and disadvantages of combination treatment with antipsychotics ECNP consensus meeting, March 2008, Nice. Eur. Neuropsychopharmacol. 19, 520-532. doi: 10.1016/j.euroneuro.2009.04.003

Harmer, C. J., Mackay, C. E., Reid, C. B., Cowen, P. J., and Goodwin, G. M. (2006). Antidepressant drug treatment modifies the neural processing of nonconscious threat cues. Biol. Psychiatry 59, 816-820. doi: 10.1016/j.biopsych.2005.10.015

Heller, A. S., Johnstone, T., Light, S. N., Peterson, M. J., Kolden, G. G., Kalin, N. H., et al. (2013). Relationships between changes in sustained fronto-striatal connectivity and positive affect in major depression resulting from antidepressant treatment. Am. J. Psychiatry 170, 197-206. doi: 10.1176/appi.ajp.2012. 12010014

Hengemihle, J. M., Abugo, O., Rifkind, J., Spangler, E., Danon, D., and Ingram, D. K. (1996). Chronic treatment with human recombinant erythropoietin increases hematocrit and improves water maze performance in mice. Physiol. Behav. 59, 153-156. doi: 10.1016/0031-9384(95)02046-2

Henschke, G., Wolf, G., and Keilhoff, G. (1993). Ketamine, but not glycine modulates quinolinate-induced neurodegeneration. Pol. J. Pharmacol. 45, 339-347.

Hercher, C., Canetti, L., Turecki, G., and Mechawar, N. (2010). Anterior cingulate pyramidal neurons display altered dendritic branching in depressed suicides. J. Psychiatr. Res. 44, 286-293. doi: 10.1016/j.jpsychires.2009.08.011

Heyes, M. P., Saito, K., Milstien, S., and Schiff, S. J. (1995). Quinolinic acid in tumors, hemorrhage and bacterial infections of the central nervous system in children. J. Neurol. Sci. 133, 112-118. doi: 10.1016/0022-510x(95)00164-w

Hill, L., and Lee, K. C. (2013). Pharmacotherapy considerations in patients with HIV and psychiatric disorders: focus on antidepressants and antipsychotics. Ann. Pharmacother. 47, 75-89. doi: 10.1345/aph.1r343

Hollon, S. D., Jarrett, R. B., Nierenberg, A. A., Thase, M. E., Trivedi, M., and Rush, A. J. (2005). Psychotherapy and medication in the treatment of adult and geriatric depression: which monotherapy or combined treatment? J. Clin. Psychiatry 66, 455-468. doi: 10.4088/jcp.v66n0408

Holm, K. J., and Markham, A. (1999). Mirtazapine: a review of its use in major depression. Drugs 57, 607-631. doi: 10.2165/00003495-199957040-00010

Holsboer, F., and Ising, M. (2010). Stress hormone regulation: biological role and translation into therapy. Annu. Rev. Psychol. 61, 81-109, C1-C11. doi: 10. 1146/annurev.psych.093008.100321 
Holtzer, R., Scarmeas, N., Wegesin, D. J., Albert, M., Brandt, J., Dubois, B., et al. (2005). Depressive symptoms in Alzheimer's disease: natural course and temporal relation to function and cognitive status. J. Am. Geriatr. Soc. 53, 20832089. doi: 10.1111/j.1532-5415.2005.00535.x

Ibrahim, L., Diazgranados, N., Franco-Chaves, J., Brutsche, N., Henter, I. D., Kronstein, P., et al. (2012a). Course of improvement in depressive symptoms to a single intravenous infusion of ketamine vs add-on riluzole: results from a 4-week, double-blind, placebo-controlled study. Neuropsychopharmacology 37, 1526-1533. doi: 10.1038/npp.2011.338

Ibrahim, L., Diaz Granados, N., Jolkovsky, L., Brutsche, N., Luckenbaugh, D. A., Herring, W. J., et al. (2012b). A randomized, placebo-controlled, crossover pilot trial of the oral selective NR2B antagonist MK-0657 in patients with treatment-resistant major depressive disorder. J. Clin. Psychopharmacol. 32, 551557. doi: 10.1097/jcp.0b013e31825d70d6

Ibrahim, L., Diazgranados, N., Luckenbaugh, D. A., Machado-Vieira, R., Baumann, J., Mallinger, A. G., et al. (2011). Rapid decrease in depressive symptoms with an N-methyl-d-aspartate antagonist in ECT-resistant major depression. Prog. Neuropsychopharmacol. Biol. Psychiatry 35, 1155-1159. doi: 10.1016/j.pnpbp. 2011.03.019

Imel, Z. E., Malterer, M. B., McKay, K. M., and Wampold, B. E. (2008). A meta-analysis of psychotherapy and medication in unipolar depression and dysthymia. J. Affect. Disord. 110, 197-206. doi: 10.1016/j.jad.2008.03.018

Irwin, S. A., and Iglewicz, A. (2010). Oral ketamine for the rapid treatment of depression and anxiety in patients receiving hospice care. J. Palliat. Med. 13, 903-908. doi: 10.1089/jpm.2010.9808

Jacob, E. L., Gatto, N. M., Thompson, A., Bordelon, Y., and Ritz, B. (2010). Occurrence of depression and anxiety prior to Parkinson's disease. Parkinsonism Relat. Disord. 16, 576-581. doi: 10.1016/j.parkreldis.2010.06.014

Jacobsen, J. P., and Mørk, A. (2004). The effect of escitalopram, desipramine, electroconvulsive seizures and lithium on brain-derived neurotrophic factor mRNA and protein expression in the rat brain and the correlation to 5-HT and 5-HIAA levels. Brain Res. 1024, 183-192. doi: 10.1016/j.brainres.2004.07.065

Jakobsen, J. C., Hansen, J. L., Simonsen, E., and Gluud, C. (2012). The effect of adding psychodynamic therapy to antidepressants in patients with major depressive disorder. A systematic review of randomized clinical trials with metaanalyses and trial sequential analyses. J. Affect. Disord. 137, 4-14. doi: 10.1016/j. jad.2011.03.035

Järventausta, K., Chrapek, W., Kampman, O., Tuohimaa, K., Björkqvist, M., Häkkinen, H., et al. (2013). Effects of s-ketamine as an anesthetic adjuvant to propofol on treatment response to electroconvulsive therapy in treatmentresistant depression: a randomized pilot study. J. ECT 29, 158-161. doi: 10. 1097/yct.0b013e318283b7e9

Ji, C., Song, C., and Zuo, P. (2011). The mechanism of memory impairment induced by $\mathrm{A} \beta$ chronic administration involves imbalance between cytokines and neurotrophins in the rat hippocampus. Curr. Alzheimer Res. 8, 410-420. doi: 10.2174/156720511795745366

Jindal, R. D. (2009). Insomnia in patients with depression: some pathophysiological and treatment considerations. CNS Drugs 23, 309-329. doi: 10.2165/00023210200923040-00004

Jurgens, H. A., Amancherla, K., and Johnson, R. W. (2012). Influenza infection induces neuroinflammation, alters hippocampal neuron morphology, and impairs cognition in adult mice. J. Neurosci. 32, 3958-3968. doi: 10. 1523/JNEUROSCI.6389-11.2012

Juul, S. E., Harcum, J., Li, Y., and Christensen, R. D. (1997). Erythropoietin is present in the cerebrospinal fluid of neonates. J. Pediatr. 130, 428-430.

Juul, S. E., Stallings, S. A., and Christensen, R. D. (1999). Erythropoietin in the cerebrospinal fluid of neonates who sustained CNS injury. Pediatr. Res. 46, 543547. doi: 10.1203/00006450-199911000-00009

Kahl, K. G., Kruse, N., Faller, H., Weiss, H., and Rieckmann, P. (2002). Expression of tumor necrosis factor-alpha and interferon-gamma mRNA in blood cells correlates with depression scores during an acute attack in patients with multiple sclerosis. Psychoneuroendocrinology 27, 671-681. doi: 10.1016/s03064530(01)00068-3

Kataoka, T. (2009). Chemical biology of inflammatory cytokine signaling. J. Antibiot. (Tokyo) 62, 655-667. doi: 10.1038/ja.2009.98

Kennard, B. D., Emslie, G. J., Mayes, T. L., Nightingale-Teresi, J., Nakonezny, P. A., Hughes, J. L., et al. (2008). Cognitive-behavioral therapy to prevent relapse in pediatric responders to pharmacotherapy for major depressive disorder.
J. Am. Acad. Child Adolesc. Psychiatry 47, 1395-1404. doi: 10.1097/CHI. 0b013e31818914a1

Köhler, S., Hoffmann, S., Unger, T., Steinacher, B., Dierstein, N., and Fydrich, T. (2013). Effectiveness of cognitive-behavioural therapy plus pharmacotherapy in inpatient treatment of depressive disorders. Clin. Psychol. Psychother. 20, 97-106. doi: $10.1002 /$ cpp.795

Kohl, Z., Winner, B., Ubhi, K., Rockenstein, E., Mante, M., Münch, M., et al. (2012). Fluoxetine rescues impaired hippocampal neurogenesis in a transgenic A53T synuclein mouse model. Eur. J. Neurosci. 35, 10-19. doi: 10.1111/j.14609568.2011.07933.x

Koo, J. W., Russo, S. J., Ferguson, D., Nestler, E. J., and Duman, R. S. (2010). Nuclear factor-kappaB is a critical mediator of stress-impaired neurogenesis and depressive behavior. Proc. Natl. Acad. Sci. U S A 107, 2669-2674. doi: 10. 1073/pnas.0910658107

Koutsouraki, E., Hatzifilipou, E., Michmizos, D., Cotsavasiloglou, C., Costa, V., and Baloyannis, S. (2011). Increase in interleukin-6 levels is related to depressive phenomena in the acute (relapsing) phase of multiple sclerosis. J. Neuropsychiatry Clin. Neurosci. 23, 442-448. doi: 10.1176/appi.neuropsych.23.4. 442

Kranaster, L., Kammerer-Ciernioch, J., Hoyer, C., and Sartorius, A. (2011). Clinically favourable effects of ketamine as an anaesthetic for electroconvulsive therapy: a retrospective study. Eur. Arch. Psychiatry Clin. Neurosci. 261, 575-582. doi: 10.1007/s00406-011-0205-7

Kranjac, D., McLinden, K. A., Deodati, L. E., Papini, M. R., Chumley, M. J., and Boehm, G. W. (2012). Peripheral bacterial endotoxin administration triggers both memory consolidation and reconsolidation deficits in mice. Brain Behav. Immun. 26, 109-121. doi: 10.1016/j.bbi.2011.08.005

Krystal, J. H., Sanacora, G., and Duman, R. S. (2013). Rapid-acting glutamatergic antidepressants: the path to ketamine and beyond. Biol. Psychiatry 73, 11331141. doi: 10.1016/j.biopsych.2013.03.026

Kumral, A., Baskin, H., Yesilirmak, D. C., Ergur, B. U., Aykan, S., Genc, S., et al. (2007). Erythropoietin attenuates lipopolysaccharide-induced white matter injury in the neonatal rat brain. Neonatology 92, 269-278. doi: 10. $1159 / 000105493$

Kumral, A., Tugyan, K., Gonenc, S., Genc, K., Genc, S., Sonmez, U., et al. (2005). Protective effects of erythropoietin against ethanol-induced apoptotic neurodegenaration and oxidative stress in the developing C57BL/6 mouse brain. Brain Res. Dev. Brain Res. 160, 146-156. doi: 10.1016/j.devbrainres.2005.08.006

Laje, G., Lally, N., Mathews, D., Brutsche, N., Chemerinski, A., Akula, N., et al. (2012). Brain-derived neurotrophic factor Val66Met polymorphism and antidepressant efficacy of ketamine in depressed patients. Biol. Psychiatry 72, e27-e28. doi: 10.1016/j.biopsych.2012.05.031

Lakshminarasimhan, H., and Chattarji, S. (2012). Stress leads to contrasting effects on the levels of brain derived neurotrophic factor in the hippocampus and amygdala. PLoS One 7:e30481. doi: 10.1371/journal.pone. 0030481

Lapidus, K. A., Soleimani, L., and Murrough, J. W. (2013). Novel glutamatergic drugs for the treatment of mood disorders. Neuropsychiatr. Dis. Treat. 9, 11011112. doi: $10.2147 /$ ndt.s36689

Larsen, M. H., Hay-Schmidt, A., Rønn, L. C., and Mikkelsen, J. D. (2008). Temporal expression of brain-derived neurotrophic factor (BDNF) mRNA in the rat hippocampus after treatment with selective and mixed monoaminergic antidepressants. Eur. J. Pharmacol. 578, 114-122. doi: 10.1016/j.ejphar.2007.08. 050

Leconte, C., Bihel, E., Lepelletier, F. X., Bouët, V., Saulnier, R., Petit, E., et al. (2011). Comparison of the effects of erythropoietin and its carbamylated derivative on behaviour and hippocampal neurogenesis in mice. Neuropharmacology 60, 354364. doi: 10.1016/j.neuropharm.2010.09.025

Li, N., Lee, B., Liu, R. J., Banasr, M., Dwyer, J. M., Iwata, M., et al. (2010). mTOR-dependent synapse formation underlies the rapid antidepressant effects of NMDA antagonists. Science 329, 959-964. doi: 10.1126/science.1190287

Li, N., Liu, R. J., Dwyer, J. M., Banasr, M., Lee, B., Son, H., et al. (2011). Glutamate N-methyl-D-aspartate receptor antagonists rapidly reverse behavioral and synaptic deficits caused by chronic stress exposure. Biol. Psychiatry 69, 754-761. doi: 10.1016/j.biopsych.2010.12.015

Liebrenz, M., Borgeat, A., Leisinger, R., and Stohler, R. (2007). Intravenous ketamine therapy in a patient with a treatment-resistant major depression. Swiss Med. Wkly. 137, 234-236. 
Liebrenz, M., Stohler, R., and Borgeat, A. (2009). Repeated intravenous ketamine therapy in a patient with treatment-resistant major depression. World J. Biol. Psychiatry 10(4 Pt 2), 640-643. doi: 10.1080/1562297070 1420481

Litteljohn, D., Mangano, E., and Hayley, S. (2010). "Common pathways to neurodegeneration and co-morbid depression," in Brain Protection in Schizophrenia, Mood and Cognitive Disorders, ed M. S. Ritsner (New York, NY: Springer), 185242.

Liu, R. J., Fuchikami, M., Dwyer, J. M., Lepack, A. E., Duman, R. S., and Aghajanian, G. K. (2013). GSK-3 inhibition potentiates the synaptogenic and antidepressantlike effects of subthreshold doses of ketamine. Neuropsychopharmacology doi: 10. 1038/npp.2013.128. [Epub ahead of print].

Liu, R. J., Lee, F. S., Li, X. Y., Bambico, F., Duman, R. S., and Aghajanian, G. K. (2012). Brain-derived neurotrophic factor Val66Met allele impairs basal and ketamine-stimulated synaptogenesis in prefrontal cortex. Biol. Psychiatry 71, 996-1005. doi: 10.1016/j.biopsych.2011.09.030

Liu, Q., Li, B., Zhu, H. Y., Wang, Y. Q., Yu, J., and Wu, G. C. (2011). Glia atrophy in the hippocampus of chronic unpredictable stress-induced depression model rats is reversed by electroacupuncture treatment. J. Affect. Disord. 128, 309-313. doi: 10.1016/j.jad.2010.07.007

Loo, C. K., Katalinic, N., Garfield, J. B., Sainsbury, K., Hadzi-Pavlovic, D., and Mac-Pherson, R. (2012). Neuropsychological and mood effects of ketamine in electroconvulsive therapy: a randomised controlled trial. J. Affect. Disord. 142, 233-240. doi: 10.1016/j.jad.2012.04.032

Loo, C., Simpson, B., and MacPherson, R. (2010). Augmentation strategies in electroconvulsive therapy. J. ECT 26, 202-207. doi: 10.1097/YCT.0b013e3181 e48143

Lynch, F. L., Dickerson, J. F., Clarke, G., Vitiello, B., Porta, G., Wagner, K. D., et al. (2011). Incremental cost-effectiveness of combined therapy vs medication only for youth with selective serotonin reuptake inhibitor-resistant depression: treatment of SSRI-resistant depression in adolescents trial findings. Arch. Gen. Psychiatry 68, 253-262. doi: 10.1001/archgenpsychiatry.2011.9

MacQueen, G. M., Campbell, S., McEwen, B. S., Macdonald, K., Amano, S., Joffe, R. T., et al. (2003). Course of illness, hippocampal function, and hippocampal volume in major depression. Proc. Natl. Acad. Sci. US A 100, 1387-1392. doi: 10. 1073/pnas.0337481100

Magariños, A. M., McEwen, B. S., Flügge, G., and Fuchs, E. (1996). Chronic psychosocial stress causes apical dendritic atrophy of hippocampal CA3 pyramidal neurons in subordinate tree shrews. J. Neurosci. 16, 3534-3540.

Malberg, J. E. (2004). Implications of adult hippocampal neurogenesis in antidepressant action. J. Psychiatry Neurosci. 29, 196-205.

Mamounas, L. A., Blue, M. E., Siuciak, J. A., and Altar, C. A. (1995). Brain-derived neurotrophic factor promotes the survival and sprouting of serotonergic axons in rat brain. J. Neurosci. 15, 7929-7939.

Marchetti, C., Tafi, E., Middei, S., Rubinacci, M. A., Restivo, L., Ammassari-Teule, M., et al. (2010). Synaptic adaptations of CAl pyramidal neurons induced by a highly effective combinational antidepressant therapy. Biol. Psychiatry 67, 146154. doi: 10.1016/j.biopsych.2009.09.017

Martínez-Turrillas, R., Del Río, J., and Frechilla, D. (2005). Sequential changes in BDNF mRNA expression and synaptic levels of AMPA receptor subunits in rat hippocampus after chronic antidepressant treatment. Neuropharmacology 49, 1178-1188. doi: 10.1016/j.neuropharm.2005.07.006

Masana, M., Castañé, A., Santana, N., Bortolozzi, A., and Artigas, F. (2012). Noradrenergic antidepressants increase cortical dopamine: potential use in augmentation strategies. Neuropharmacology 63, 675-684. doi: 10.1016/j.neuropharm. 2012.05.020

Masi, G., and Brovedani, P. (2011). The hippocampus, neurotrophic factors and depression: possible implications for the pharmacotherapy of depression. CNS Drugs 25, 913-931. doi: 10.2165/11595900-000000000-00000

Mathew, S. J., Murrough, J. W., aan het Rot, M., Collins, K. A., Reich, D. L., and Charney, D. S. (2010). Riluzole for relapse prevention following intravenous ketamine in treatment-resistant depression: a pilot randomized, placebocontrolled continuation trial. Int. J. Neuropsychopharmacol. 13, 71-82. doi: 10. 1017/s1461145709000169

Mayberg, H. S., Brannan, S. K., Tekell, J. L., Silva, J. A., Mahurin, R. K., McGinnis, S., et al. (2000). Regional metabolic effects of fluoxetine in major depression: serial changes and relationship to clinical response. Biol. Psychiatry 48, 830-843. doi: 10.1016/s0006-3223(00)01036-2
McEwen, B. S. (2005). Glucocorticoids, depression, and mood disorders: structural remodeling in the brain. Metabolism 54(Suppl. 1), 20-23. doi: 10.1016/j. metabol.2005.01.008

Mercier, G., Lennon, A. M., Renouf, B., Dessouroux, A., Ramaugé, M., Courtin, F., et al. (2004). MAP kinase activation by fluoxetine and its relation to gene expression in cultured rat astrocytes. J. Mol. Neurosci. 24, 207-216. doi: 10. 1385/JMN:24:2:207

Meng, R., Zhu, D., Bi, Y., Yang, D., and Wang, Y. (2013). Erythropoietin inhibits gluconeogenesis and inflammation in the liver and improves glucose intolerance in high-fat diet-fed mice. PLoS One 8:e53557. doi: 10.1371/journal.pone. 0053557

Mengozzi, M., Cervellini, I., Villa, P., Erbayraktar, Z., Gökmen, N., Yilmaz, O., et al. (2012). Erythropoietin-induced changes in brain gene expression reveal induction of synaptic plasticity genes in experimental stroke. Proc. Natl. Acad. Sci. U S A 109, 9617-9622. doi: 10.1073/pnas.1200554109

Messer, M., Haller, I. V., Larson, P., Pattison-Crisostomo, J., and Gessert, C. E. (2010). The use of a series of ketamine infusions in two patients with treatmentresistant depression. J. Neuropsychiatry Clin. Neurosci. 22, 442-444. doi: 10. 1176/appi.neuropsych.22.4.442

Michel, T. M., Frangou, S., Camara, S., Thiemeyer, D., Jecel, J., Tatschner, T., et al. (2008). Altered glial cell line-derived neurotrophic factor (GDNF) concentrations in the brain of patients with depressive disorder: a comparative postmortem study. Eur. Psychiatry 23, 413-420. doi: 10.1016/j.eurpsy.2008.06.001

Mion, G., and Villevieille, T. (2013). Ketamine pharmacology: an update (pharmacodynamics and molecular aspects, recent findings). CNS Neurosci. Ther. 19, 370-380. doi: 10.1111/cns.12099

Miskowiak, K. W., Favaron, E., Hafizi, S., Inkster, B., Goodwin, G. M., Cowen, P. J., et al. (2009). Effects of erythropoietin on emotional processing biases in patients with major depression: an exploratory fMRI study. Psychopharmacology (Berl) 207, 133-142. doi: 10.1007/s00213-009-1641-1

Miskowiak, K. W., Favaron, E., Hafizi, S., Inkster, B., Goodwin, G. M., Cowen, P. J., et al. (2010). Erythropoietin modulates neural and cognitive processing of emotional information in biomarker models of antidepressant drug action in depressed patients. Psychopharmacology (Berl) 210, 419-428. doi: 10. 1007/s00213-010-1842-7

Miskowiak, K., O'Sullivan, U., and Harmer, C. J. (2007). Erythropoietin reduces neural and cognitive processing of fear in human models of antidepressant drug action. Biol. Psychiatry 62, 1244-1250. . doi: 10.1016/j.biopsych.2007.01.011

Miskowiak, K. W., Vinberg, M., Harmer, C. J., Ehrenreich, H., and Kessing, L. V. (2012). Erythropoietin: a candidate treatment for mood symptoms and memory dysfunction in depression. Psychopharmacology (Berl) 219, 687-698. doi: 10 . 1007/s00213-011-2511-1

Mitra, A., Bansal, S., Wang, W., Falk, S., Zolty, E., and Schrier, R. W. (2007). Erythropoietin ameliorates renal dysfunction during endotoxaemia. Nephrol. Dial. Transplant. 22, 2349-2353. doi: 10.1093/ndt/gfm 216

Murphy, S. E., Yiend, J., Lester, K. J., Cowen, P. J., and Harmer, C. J. (2009). Shortterm serotonergic but not noradrenergic antidepressant administration reduces attentional vigilance to threat in healthy volunteers. Int. J. Neuropsychopharmacol. 12, 169-179. doi: 10.1017/s1461145708009164

Murrough, J. W., Perez, A. M., Pillemer, S., Stern, J., Parides, M. K., Aan Het Rot, M., et al. (2013). Rapid and longer-term antidepressant effects of repeated ketamine infusions in treatment-resistant major depression. Biol. Psychiatry 74, 250-256. doi: 10.1016/j.biopsych.2012.06.022

Musazzi, L., Cattaneo, A., Tardito, D., Barbon, A., Gennarelli, M., Barlati, S., et al. (2009). Early raise of BDNF in hippocampus suggests induction of posttranscriptional mechanisms by antidepressants. BMC Neurosci. 10:48. doi: 10 . 1186/1471-2202-10-48

Nadam, J., Navarro, F., Sanchez, P., Moulin, C., Georges, B., Laglaine, A., et al. (2007). Neuroprotective effects of erythropoietin in the rat hippocampus after pilocarpine-induced status epilepticus. Neurobiol. Dis. 25, 412-426. doi: 10. 1016/j.nbd.2006.10.009

Nairz, M., Schroll, A., Moschen, A. R., Sonnweber, T., Theurl, M., Theurl, I., et al. (2011). Erythropoietin contrastingly affects bacterial infection and experimental colitis by inhibiting nuclear factor $-\kappa \mathrm{B}$-inducible immune pathways. Immunity 34, 61-74. doi: 10.1016/j.immuni.2011.01.002

Nairz, M., Sonnweber, T., Schroll, A., Theurl, I., and Weiss, G. (2012). The pleiotropic effects of erythropoietin in infection and inflammation. Microbes Infect. 14, 238-246. doi: 10.1016/j.micinf.2011.10.005 
Nations, K. R., Dogterom, P., Bursi, R., Schipper, J., Greenwald, S., Zraket, D., et al. (2012). Examination of Org 26576, an AMPA receptor positive allosteric modulator, in patients diagnosed with major depressive disorder: an exploratory, randomized, double-blind, placebo-controlled trial. J. Psychopharmacol. 26, 1525-1539. doi: 10.1177/0269881112458728

Nelson, J. C., and Papakostas, G. I. (2009). Atypical antipsychotic augmentation in major depressive disorder: a meta-analysis of placebo-controlled randomized trials. Am. J. Psychiatry 166, 980-991. doi: 10.1176/appi.ajp.2009.0903 0312

Okamoto, N., Nakai, T., Sakamoto, K., Nagafusa, Y., Higuchi, T., and Nishikawa, T. (2010). Rapid antidepressant effect of ketamine anesthesia during electroconvulsive therapy of treatment-resistant depression: comparing ketamine and propofol anesthesia. J. ECT 26, 223-227. doi: 10.1097/yct.0b013e3181c3b0aa

Osborn, M., Rustom, N., Clarke, M., Litteljohn, D., Rudyk, C., Anisman, H., et al. (2013). Antidepressant-like effects of erythropoietin: a focus on behavioural and hippocampal processes. PLoS One 8:e72813. doi: 10.1371/journal.pone.0072813

Otsuki, K., Uchida, S., Watanuki, T., Wakabayashi, Y., Fujimoto, M., Matsubara, T., et al. (2008). Altered expression of neurotrophic factors in patients with major depression. J. Psychiatr. Res. 42, 1145-1153. doi: 10.1016/j.jpsychires.2008.01. 010

Ou, L. C., and Gean, P. W. (2006). Regulation of amygdala-dependent learning by brain-derived neurotrophic factor is mediated by extracellular signal-regulated kinase and phosphatidylinositol-3-kinase. Neuropsychopharmacology 31, 287296. doi: 10.1038/sj.npp.1300830

Owenby, R. K., Brown, L. T., and Brown, J. N. (2011). Use of risperidone as augmentation treatment for major depressive disorder. Ann. Pharmacother. 45, 95-100. doi: 10.1345/aph.1p397

Ozmenler, N. K., Karlidere, T., Bozkurt, A., Yetkin, S., Doruk, A., Sutcigil, L., et al. (2008). Mirtazapine augmentation in depressed patients with sexual dysfunction due to selective serotonin reuptake inhibitors. Hum. Psychopharmacol. 23, 321-326. doi: 10.1002/hup.929

Pandey, G. N., Dwivedi, Y., Rizavi, H. S., Ren, X., Zhang, H., and Pavuluri, M. N. (2010). Brain-derived neurotrophic factor gene and protein expression in pediatric and adult depressed subjects. Prog. Neuropsychopharmacol. Biol. Psychiatry 34, 645-651. doi: 10.1016/j.pnpbp.2010.04.026

Pardridge, W. M., Kang, Y. S., and Buciak, J. L. (1994). Transport of human recombinant brain-derived neurotrophic factor (BDNF) through the rat bloodbrain barrier in vivo using vector-mediated peptide drug delivery. Pharm. Res. 11, 738-746. doi: 10.1023/A:1018940732550

Paul, R., Schaaff, N., Padberg, F., Möller, H. J., and Frodl, T. (2009). Comparison of racemic ketamine and S-ketamine in treatment-resistant major depression: report of two cases. World J. Biol. Psychiatry 10, 241-244. doi: 10 $1080 / 15622970701714370$

Pezet, S., and McMahon, S. B. (2006). Neurotrophins: mediators and modulators of pain. Annu. Rev. Neurosci. 29, 507-538. doi: 10.1146/annurev.neuro.29.051605. 112929

Phani, S., Loike, J. D., and Przedborski, S. (2012). Neurodegeneration and inflammation in Parkinson's disease. Parkinsonism Relat. Disord. 18(Suppl. 1), S207S209. doi: 10.1016/s1353-8020(11)70064-5

Piccinni, A., Marazziti, D., Catena, M., Domenici, L., Del Debbio, A., Bianchi, C., et al. (2008). Plasma and serum brain-derived neurotrophic factor (BDNF) in depressed patients during 1 year of antidepressant treatments. J. Affect. Disord. 105, 279-283. doi: 10.1016/j.jad.2007.05.005

Pilar-Cuéllar, F., Vidal, R., and Pazos, A. (2012). Subchronic treatment with fluoxetine and ketanserin increases hippocampal brain-derived neurotrophic factor, $\beta$-catenin and antidepressant-like effects. Br. J. Pharmacol. 165, 10461057. doi: 10.1111/j.1476-5381.2011.01516.x

Pilc, A., Wieronska, J. M., and Skolnick, P. (2013). Glutamate-based antidepressants: preclinical psychopharmacology. Biol. Psychiatry 73, 1125-1132. doi: 10 1016/j.biopsych.2013.01.021

Preskorn, S. H., Baker, B., Kolluri, S., Menniti, F. S., Krams, M., and Landen, J. W. (2008). An innovative design to establish proof of concept of the antidepressant effects of the NR2B subunit selective N-methyl-D-aspartate antagonist, CP-101,606, in patients with treatment-refractory major depressive disorder. J. Clin. Psychopharmacol. 28, 631-637. doi: 10.1097/JCP.0b013e31818 abcea

Price, R. B., Nock, M. K., Charney, D. S., and Mathew, S. J. (2009). Effects of intravenous ketamine on explicit and implicit measures of suicidality in treatment-resistant depression. Biol. Psychiatry 66, 522-526. doi: 10.1016/j. biopsych.2009.04.029

Quidé, Y., Witteveen, A. B., El-Hage, W., Veltman, D. J., and Olff, M. (2012). Differences between effects of psychological versus pharmacological treatments on functional and morphological brain alterations in anxiety disorders and major depressive disorder: a systematic review. Neurosci. Biobehav. Rev. 36, 626644. doi: 10.1016/j.neubiorev.2011.09.004

Raichle, M. E., MacLeod, A. M., Snyder, A. Z., Powers, W. J., Gusnard, D. A., and Shulman, G. L. (2001). A default mode of brain function. Proc. Natl. Acad. Sci. U S A 98, 676-682. doi: 10.1073/pnas.98.2.676

Rajkowska, G. (2000). Postmortem studies in mood disorders indicate altered numbers of neurons and glial cells. Biol. Psychiatry 48, 766-777. doi: 10. 1016/s0006-3223(00)00950-1

Rajkowska, G., Miguel-Hidalgo, J. J., Wei, J., Dilley, G., Pittman, S. D., Meltzer, H. Y., et al. (1999). Morphometric evidence for neuronal and glial prefrontal cell pathology in major depression. Biol. Psychiatry 45, 1085-1098. doi: 10. 1016/s0006-3223(99)00041-4

Rattiner, L. M., Davis, M., French, C. T., and Ressler, K. J. (2004). Brain-derived neurotrophic factor and tyrosine kinase receptor B involvement in amygdaladependent fear conditioning. J. Neurosci. 24, 4796-4806. doi: 10.1523/jneurosci. 5654-03.2004

Reeves, H., Batra, S., May, R. S., Zhang, R., Dahl, D. C., and Li, X. (2008). Efficacy of risperidone augmentation to antidepressants in the management of suicidality in major depressive disorder: a randomized, double-blind, placebocontrolled pilot study. J. Clin. Psychiatry 69, 1228-1336. doi: 10.4088/jcp. v69n0805

Réus, G. Z., Stringari, R. B., Ribeiro, K. F., Ferraro, A. K., Vitto, M. F., Cesconetto, P., et al. (2011). Ketamine plus imipramine treatment induces antidepressantlike behavior and increases CREB and BDNF protein levels and PKA and PKC phosphorylation in rat brain. Behav. Brain Res. 221, 166-171. doi: 10.1016/j.bbr. 2011.02.024

Reynolds, A. D., Glanzer, J. G., Kadiu, I., Ricardo-Dukelow, M., Chaudhuri, A., Ciborowski, P., et al. (2008). Nitrated alpha-synuclein-activated microglial profiling for Parkinson's disease. J. Neurochem. 104, 1504-1525. doi: 10.1111/j. 1471-4159.2007.05087.x

Ritchey, M., Dolcos, F., Eddington, K. M., Strauman, T. J., and Cabeza, R. (2011). Neural correlates of emotional processing in depression: changes with cognitive behavioral therapy and predictors of treatment response. J. Psychiatr. Res. 45, 577-587. doi: 10.1016/j.jpsychires.2010.09.007

Rogóz, Z., and Legutko, B. (2005). Combined treatment with imipramine and metyrapone induces hippocampal and cortical brain-derived neurotrophic factor gene expression in rats. Pharmacol. Rep. 57, 840-844.

Rojas, P. S., Fritsch, R., Rojas, R. A., Jara, P., and Fiedler, J. L. (2011). Serum brainderived neurotrophic factor and glucocorticoid receptor levels in lymphocytes as markers of antidepressant response in major depressive patients: a pilot study. Psychiatry Res. 189, 239-245. doi: 10.1016/j.psychres.2011.04.032

Rojo, A., Aguilar, M., Garolera, M. T., Cubo, E., Navas, I., and Quintana, S. (2003). Depression in Parkinson's disease: clinical correlates and outcome. Parkinsonism Relat. Disord. 10, 23-28. doi: 10.1016/s1353-8020(03)00067-1

Sacher, J., Neumann, J., Fünfstück, T., Soliman, A., Villringer, A., and Schroeter, M. L. (2012). Mapping the depressed brain: a meta-analysis of structural and functional alterations in major depressive disorder. J. Affect. Disord. 140, 142148. doi: 10.1016/j.jad.2011.08.001

Sakai, T., Ichiyama, T., Whitten, C. W., Giesecke, A. H., and Lipton, J. M. (2000). Ketamine suppresses endotoxin-induced NF-kappaB expression. Can. J. Anaesth. 47, 1019-1024. doi: 10.1007/BF03024876

Sakanaka, M., Wen, T. C., Matsuda, S., Masuda, S., Morishita, E., Nagao, M., et al. (1998). In vivo evidence that erythropoietin protects neurons from ischemic damage. Proc. Natl. Acad. Sci. U S A 95, 4635-4640. doi: 10.1073/pnas.95.8. 4635

Sanchez, P. E., Navarro, F. P., Fares, R. P., Nadam, J., Georges, B., Moulin, C., et al. (2009). Erythropoietin receptor expression is concordant with erythropoietin but not with common beta chain expression in the rat brain throughout the life span. J. Comp. Neurol. 514, 403-414. doi: 10.1002/cne.22020

Sani, G., Serra, G., Kotzalidis, G. D., Romano, S., Tamorri, S. M., Manfredi, G., et al. (2012). The role of memantine in the treatment of psychiatric disorders other than the dementias: a review of current preclinical and clinical evidence. CNS Drugs 26, 663-690. doi: 10.2165/11634390-000000000-00000 
Sapolsky, R. M., Uno, H., Rebert, C. S., and Finch, C. E. (1990). Hippocampal damage associated with prolonged glucocorticoid exposure in primates. $J$. Neurosci. 10, 2897-2902.

Sargin, D., Friedrichs, H., El-Kordi, A., and Ehrenreich, H. (2010). Erythropoietin as neuroprotective and neuroregenerative treatment strategy: comprehensive overview of 12 years of preclinical and clinical research. Best Pract. Res. Clin. Anaesthesiol. 24, 573-594. doi: 10.1016/j.bpa.2010.10.005

Scheidegger, M., Walter, M., Lehmann, M., Metzger, C., Grimm, S., Boeker, H., et al. (2012). Ketamine decreases resting state functional network connectivity in healthy subjects: implications for antidepressant drug action. PLoS One 7:e44799. doi: 10.1371/journal.pone.0044799

Schloesser, R. J., Lehmann, M., Martinowich, K., Manji, H. K., and Herkenham, M. (2010). Environmental enrichment requires adult neurogenesis to facilitate the recovery from psychosocial stress. Mol. Psychiatry 15, 1152-1163. doi: 10. 1038/mp.2010.34

Schlösser, R. G., Wagner, G., Koch, K., Dahnke, R., Reichenbach, J. R., and Sauer, H. (2008). Fronto-cingulate effective connectivity in major depression: a study with fMRI and dynamic causal modeling. Neuroimage 43, 645-655. doi: 10.1016/j. neuroimage.2008.08.002

Shang, Y., Li, X., Prasad, P. V., Xu, S., Yao, S., Liu, D., et al. (2009). Erythropoietin attenuates lung injury in lipopolysaccharide treated rats. J. Surg. Res. 155, 104110. doi: 10.1016/j.jss.2008.10.003

Sheline, Y. I., Barch, D. M., Price, J. L., Rundle, M. M., Vaishnavi, S. N., Snyder, A. Z., et al. (2009). The default mode network and self-referential processes in depression. Proc. Natl. Acad. Sci. U S A 106, 1942-1947. doi: 10.1073/pnas. 0812686106

Shirayama, Y., Chen, A. C., Nakagawa, S., Russell, D. S., and Duman, R. S. (2002). Brain-derived neurotrophic factor produces antidepressant effects in behavioral models of depression. J. Neurosci. 22, 3251-3261.

Siegert, R. J., and Abernethy, D. A. (2005). Depression in multiple sclerosis: a review. J. Neurol. Neurosurg. Psychiatry 76, 469-475. doi: 10.1037/0894-4105. 19.2.152.supp

Sliz, D., and Hayley, S. (2012). Major depressive disorder and alterations in insular cortical activity: a review of current functional magnetic imaging research. Front. Hum. Neurosci. 6:323. doi: 10.3389/fnhum.2012.00323

Son, H., Banasr, M., Choi, M., Chae, S. Y., Licznerski, P., Lee, B., et al. (2012). Neuritin produces antidepressant actions and blocks the neuronal and behavioral deficits caused by chronic stress. Proc. Natl. Acad. Sci. U S A 109, 11378-11383. doi: 10.1073/pnas.1201191109

Spalding, K. L., Bergmann, O., Alkass, K., Bernard, S., Salehpour, M., Huttner, H. B., et al. (2013). Dynamics of hippocampal neurogenesis in adult humans. Cell 153, 1219-1227. doi: 10.1016/j.cell.2013.05.002

Steiner, J., Bielau, H., Brisch, R., Danos, P., Ullrich, O., Mawrin, C., et al. (2008). Immunological aspects in the neurobiology of suicide: elevated microglial density in schizophrenia and depression is associated with suicide. J. Psychiatr. Res. 42, 151-157. doi: 10.1016/j.jpsychires.2006.10.013

Steiner, J., Walter, M., Gos, T., Guillemin, G. J., Bernstein, H. G., Sarnyai, Z., et al. (2011). Severe depression is associated with increased microglial quinolinic acid in subregions of the anterior cingulate gyrus: evidence for an immune-modulated glutamatergic neurotransmission? J. Neuroinflammation 8:94. doi: 10.1186/1742-2094-8-94

Sun, J., Li, F., Chen, J., and Xu, J. (2004). Effect of ketamine on NF-kappa B activity and TNF-alpha production in endotoxin-treated rats. Ann. Clin. Lab. Sci. 34, 181-186.

Takebayashi, M., Hisaoka, K., Nishida, A., Tsuchioka, M., Miyoshi, I., Kozuru, T., et al. (2006). Decreased levels of whole blood glial cell linederived neurotrophic factor (GDNF) in remitted patients with mood disorders. Int. J. Neuropsychopharmacol. 9, 607-612. doi: 10.1017/s146114570 5006085

Takenaka, I., Ogata, M., Koga, K., Matsumoto, T., and Shigematsu, A. (1994). Ketamine suppresses endotoxin-induced tumor necrosis factor alpha production in mice. Anesthesiology 80, 402-408. doi: 10.1097/00000542-19940200000020

Tan, S., Lam, W. P., Wai, M. S., Yu, W. H., and Yew, D. T. (2012). Chronic ketamine administration modulates midbrain dopamine system in mice. PLoS One 7:e43947. doi: 10.1371/journal.pone.0043947

Tata, D. A., and Anderson, B. J. (2010). The effects of chronic glucocorticoid exposure on dendritic length, synapse numbers and glial volume in animal models: implications for hippocampal volume reductions in depression. Physiol. Behav. 99, 186-193. doi: 10.1016/j.physbeh.2009.09.008

Teixeira, A. L., Barbosa, I. G., Diniz, B. S., and Kummer, A. (2010). Circulating levels of brain-derived neurotrophic factor: correlation with mood, cognition and motor function. Biomark. Med. 4, 871-887. doi: 10.2217/bmm.10.111

Trivedi, M. H., Thase, M. E., Fava, M., Nelson, C. J., Yang, H., Qi, Y., et al. (2008). Adjunctive aripiprazole in major depressive disorder: analysis of efficacy and safety in patients with anxious and atypical features. J. Clin. Psychiatry 69, 19281936. doi: 10.4088/jcp.v69n1211

Tseng, P. T., Lee, Y., and Lin, P. Y. (2013). Age-associated decrease in serum glial cell line-derived neurotrophic factor levels in patients with major depressive disorder. Prog. Neuropsychopharmacol. Biol. Psychiatry 40, 334-339. doi: 10. 1016/j.pnpbp.2012.12.002

Uchida, S., Hara, K., Kobayashi, A., Otsuki, K., Yamagata, H., Hobara, T., et al. (2011). Epigenetic status of Gdnf in the ventral striatum determines susceptibility and adaptation to daily stressful events. Neuron 69, 359-372. doi: 10.1016/j. neuron.2010.12.023

von Wolff, A., Hölzel, L. P., Westphal, A., Härter, M., and Kriston, L. (2012). Combination of pharmacotherapy and psychotherapy in the treatment of chronic depression: a systematic review and meta-analysis. BMC Psychiatry 12:61. doi: 10.1186/1471-244X-12-61

Vyas, A., Mitra, R., Shankaranarayana Rao, B. S., and Chattarji, S. (2002). Chronic stress induces contrasting patterns of dendritic remodeling in hippocampal and amygdaloid neurons. J. Neurosci. 22, 6810-6818.

Wang, X., Chen, Y., Zhou, X., Liu, F., Zhang, T., and Zhang, C. (2012). Effects of propofol and ketamine as combined anesthesia for electroconvulsive therapy in patients with depressive disorder. J. ECT 28, 128-132. doi: 10.1097/YCT. 0b013e31824d1d02

Wang, X., Hou, Z., Yuan, Y., Hou, G., Liu, Y., Li, H., et al. (2011a). Association study between plasma GDNF and cognitive function in late-onset depression. J. Affect. Disord. 132, 418-421. doi: 10.1016/j.jad.2011.03.043

Wang, X., Yang, Y., Zhou, X., Wu, J., Li, J., Jiang, X., et al. (2011b). Propofol pretreatment increases antidepressant-like effects induced by acute administration of ketamine in rats receiving forced swimming test. Psychiatry Res. 185, 248-253. doi: 10.1016/j.psychres.2010.04.046

Wang, L., Zhang, Z., Wang, Y., Zhang, R., and Chopp, M. (2004). Treatment of stroke with erythropoietin enhances neurogenesis and angiogenesis and improves neurological function in rats. Stroke 35, 1732-1737. doi: 10.1161/01. str.0000132196.49028.a4

Wiles, N., Thomas, L., Abel, A., Ridgway, N., Turner, N., Campbell, J., et al. (2013). Cognitive behavioural therapy as an adjunct to pharmacotherapy for primary care based patients with treatment resistant depression: results of the CoBalT randomised controlled trial. Lancet 381, 375-384. doi: 10.1016/s01406736(12)61552-9

Wilms, H., Schwabedissen, B., Sievers, J., and Lucius, R. (2009). Erythropoietin does not attenuate cytokine production and inflammation in microglia-implications for the neuroprotective effect of erythropoietin in neurological diseases. J. Neuroimmunol. 212, 106-111. doi: 10.1016/j.jneuroim.2009.04.018

Wu, W. T., Hu, T. M., Lin, N. T., Subeq, Y. M., Lee, R. P., and Hsu, B. G. (2010). Lowdose erythropoietin aggravates endotoxin-induced organ damage in conscious rats. Cytokine 49, 155-162. doi: 10.1016/j.cyto.2009.11.002

Wu, Y., Li, W., Zhou, C., Lu, F., Gao, T., Liu, Y., et al. (2012). Ketamine inhibits lipopolysaccharide-induced astrocytes activation by suppressing TLR4/NF- $\kappa \mathrm{B}$ pathway. Cell. Physiol. Biochem. 30, 609-617. doi: 10.1159/000341442

Xu, H., Chen, Z., He, J., Haimanot, S., Li, X., Dyck, L., et al. (2006). Synergetic effects of quetiapine and venlafaxine in preventing the chronic restraint stressinduced decrease in cell proliferation and BDNF expression in rat hippocampus. Hippocampus 16, 551-559. doi: 10.1002/hipo.20184

Yamanishi, T., Tachibana, H., Oguru, M., Matsui, K., Toda, K., Okuda, B., et al. (2013). Anxiety and depression in patients with Parkinson's disease. Intern. Med. 52, 539-545. doi: 10.2169/internalmedicine.52.8617

Yan, H. C., Cao, X., Gao, T. M., and Zhu, X. H. (2011). Promoting adult hippocampal neurogenesis: a novel strategy for antidepressant drug screening. Curr. Med. Chem. 18, 4359-4367. doi: 10.2174/092986711797200471

Yang, C., Li, X., Wang, N., Xu, S., Yang, J., and Zhou, Z. (2012). Tramadol reinforces antidepressant effects of ketamine with increased levels of brain-derived neurotrophic factor and tropomyosin-related kinase B in rat hippocampus. Front. Med. 6, 411-415. doi: 10.1007/s11684-012-0226-2 
Yang, C., Shen, J., Hong, T., Hu, T. T., Li, Z. J., Zhang, H. T., et al. (2013). Effects of ketamine on lipopolysaccharide-induced depressive-like behavior and the expression of inflammatory cytokines in the rat prefrontal cortex. Mol. Med. Rep. 8, 887-890. doi: 10.3892/mmr.2013.1600

Ye, Y., Wang, G., Wang, H., and Wang, X. (2011). Brain-derived neurotrophic factor (BDNF) infusion restored astrocytic plasticity in the hippocampus of a rat model of depression. Neurosci. Lett. 503, 15-19. doi: 10.1016/j.neulet.2011. 07.055

Yoshida, T., Ishikawa, M., Niitsu, T., Nakazato, M., Watanabe, H., Shiraishi, T., et al. (2012). Decreased serum levels of mature brain-derived neurotrophic factor (BDNF), but not its precursor proBDNF, in patients with major depressive disorder. PLoS One 7:e42676. doi: 10.1371/journal.pone.0042676

Yoshimura, S., Okamoto, Y., Onoda, K., Matsunaga, M., Okada, G., Kunisato, Y., et al. (2013). Cognitive behavioral therapy for depression changes medial prefrontal and ventral anterior cingulate cortex activity associated with selfreferential processing. Soc. Cogn. Affect. Neurosci. doi: 10.1093/scan/nst009. [Epub ahead of print].

Yuan, R., Maeda, Y., Li, W., Lu, W., Cook, S., and Dowling, P. (2008). Erythropoietin: a potent inducer of peripheral immuno/inflammatory modulation in autoimmune EAE. PLoS One 3:e1924. doi: 10.1371/journal.pone.000 1924

Zarate, Jr. C. A., Mathews, D., Ibrahim, L., Chaves, J. F., Marquardt, C., Ukoh, I., et al. (2013). A randomized trial of a low-trapping nonselective N-methyld-aspartate channel blocker in major depression. Biol. Psychiatry 74, 257-264. doi: 10.1016/j.biopsych.2012.10.019

Zarate, Jr. C. A., Singh, J. B., Carlson, P. J., Brutsche, N. E., Ameli, R., Luckenbaugh, D. A., et al. (2006). A randomized trial of an N-methyl-D-aspartate antagonist in treatment-resistant major depression. Arch. Gen. Psychiatry 63, 856-864. doi: 10. 1001/archpsyc.63.8.856

Zhang, Y., Gu, F., Chen, J., and Dong, W. (2010). Chronic antidepressant administration alleviates frontal and hippocampal BDNF deficits in CUMS rat. Brain Res. 1366, 141-148. doi: 10.1016/j.brainres.2010.09.095

Zhang, F., Wang, S., Cao, G., Gao, Y., and Chen, J. (2007). Signal transducers and activators of transcription 5 contributes to erythropoietin-mediated neuroprotection against hippocampal neuronal death after transient global cerebral ischemia. Neurobiol. Dis. 25, 45-53. doi: 10.1016/j.nbd.2006.08.007

Zhang, Y., Xiong, Y., Mahmood, A., Meng, Y., Qu, C., Schallert, T., et al. (2009). Therapeutic effects of erythropoietin on histological and functional outcomes following traumatic brain injury in rats are independent of hematocrit. Brain Res. 1294, 153-164. doi: 10.1016/j.brainres.2009.07.077

Zhang, X., Zhang, Z., Sha, W., Xie, C., Xi, G., Zhou, H., et al. (2009). Electroconvulsive therapy increases glial cell-line derived neurotrophic factor (GDNF) serum levels in patients with drug-resistant depression. Psychiatry Res. 170, 273-275. doi: 10.1016/j.psychres.2009.01.011

Zhang, X., Zhang, Z., Xie, C., Xi, G., Zhou, H., Zhang, Y., et al. (2008). Effect of treatment on serum glial cell line-derived neurotrophic factor in depressed patients. Prog. Neuropsychopharmacol. Biol. Psychiatry 32, 886-890. doi: 10. 1016/j.pnpbp.2008.01.004

Zheng, F., Zhou, X., Moon, C., and Wang, H. (2012). Regulation of brainderived neurotrophic factor expression in neurons. Int. J. Physiol. Pathophysiol. Pharmacol. 4, 188-200.

Conflict of Interest Statement: The authors declare that the research was conducted in the absence of any commercial or financial relationships that could be construed as a potential conflict of interest.

Received: 17 April 2013; accepted: 29 October 2013; published online: 20 November 2013.

Citation: Hayley S and Litteljohn D (2013) Neuroplasticity and the next wave of antidepressant strategies. Front. Cell. Neurosci. 7:218. doi: 10.3389/fncel.2013.00218 This article was submitted to the journal Frontiers in Cellular Neuroscience.

Copyright (c) 2013 Hayley and Litteljohn. This is an open-access article distributed under the terms of the Creative Commons Attribution License (CC BY). The use, distribution or reproduction in other forums is permitted, provided the original author(s) or licensor are credited and that the original publication in this journal is cited, in accordance with accepted academic practice. No use, distribution or reproduction is permitted which does not comply with these terms. 